VALTER LUIZ VENDRAMIN

AUTOMAÇÃO DE SISTEMAS NA ADMINISTRAÇÃO PÚBLICA DO MUNICÍPIO DE SÃO PAULO

São Paulo

2012 
VALTER LUIZ VENDRAMIN

\section{AUTOMAÇÃO DE SISTEMAS NA ADMINISTRAÇÃO PÚBLICA DO MUNICÍPIO DE SÃO PAULO}

Dissertação apresentada à Escola Politécnica da Universidade de São Paulo para obtenção do título de Mestre em Ciências

São Paulo 


\section{AUTOMAÇÃO DE SISTEMAS NA ADMINISTRAÇÃO PÚBLICA DO MUNICÍPIO DE SÃO PAULO}

Dissertação apresentada à Escola Politécnica da Universidade de São Paulo para obtenção do título de Mestre em Ciências

Área de concentração: Engenharia de Energia e Automação Elétricas

Orientador: Prof. Dr. Eduardo Mario Dias

São Paulo 
VENDRAMIN, V. L. Automação de sistemas na administração pública do município de São Paulo. Dissertação apresentada à Escola Politécnica da Universidade de São Paulo para obtenção do título de Mestre em Ciências.

Aprovado em:

Banca Examinadora

Prof. Dr, Instituição:

Julgamento:

Assinatura:

Prof. Dr, Instituição:

Julgamento:

Assinatura:

Prof. Dr,

Instituição:

Julgamento:

Assinatura:

Prof. Dr, Instituição:

Julgamento:

Assinatura:

Prof. Dr, Instituição:

Julgamento: Assinatura: 
Dedico este trabalho a minha esposa Soraia, ao meu filho Luiz Gustavo e a minha filha Giovana Clara. 


\section{AGRADECIMENTOS}

Ao Professor Doutor Eduardo Mário Dias, mais que um orientador, um verdadeiro amigo.

Aos doutores Caio Fernando Fontana, Akio Sakurai e Vidal Melo.

Aos colegas da USP e da Prefeitura de São Paulo pelas informações relevantes que ajudaram a construir esta dissertação. 


\section{RESUMO}

Neste trabalho é apresentado um modelo de automação a ser implementado em serviços da administração pública, com vistas a agilizar os trâmites da burocracia necessária a sua realização, contribuindo para uma mudança da visão dos usuários a respeito da divulgada morosidade administrativa. Com este propósito, o objetivo do modelo é diminuir o tempo entre a coleta de dados, a tabulação e a tomada de decisão por parte do administrador público. O conceito de automação utilizado é o apresentado por Cícero Couto de Moraes e Plínio Benedito de Lauro Castrucci, entendendo-se a propriedade de sua adoção na administração pública pela via do desenvolvimento de processos. A metodologia apresentada propõe desenvolvimento paralelo e concomitante de ações, ainda que considerando a forma serial com que estas são realizadas na atual administração pública, organizada em esquema piramidal. Além disto, o modelo baseia-se na implantação de um sistema de gestão de um banco de dados alimentado pelos diversos atores que exercem as mais variadas atividades do processo, dispensando a assinatura formal em todos os documentos e requisitando, apenas, a identidade eletrônica dos envolvidos. Um outro diferencial é a acessibilidade possibilitada a todos os funcionários envolvidos, independentemente de seu grau de instrução. Este trabalho apresenta as diretrizes norteadoras do modelo de automação proposto e sua logística de implantação, citando as diversas tecnologias existentes e possíveis de serem aplicadas na automação dos serviços da administração pública; exemplifica a possibilidade de automação na administração pública com a sistemática de trabalho implantada no Departamento de Edificações do Município de São Paulo. A metodologia proposta revela a ocorrência de reduções consideráveis nos prazos e custos finais dos serviços executados, na confiabilidade dos resultados, na qualidade da apresentação do produto final de forma padronizada e, principalmente, no poder de gestão que o processo propicia aos gestores de todos os níveis hierárquicos. Outra grande vantagem do sistema é que ele se adapta a qualquer situação de trabalho, seja ela técnica ou administrativa, interpondo dados de áreas afins, sempre que necessário, e proporcionando resultados que podem ser utilizados desde a gestão superior até sua disponibilização para a população, via Internet ou sala de situação. Além disto, a atualização automática de dados possibilita agilidade em possíveis correções de rumo, aspecto especialmente valioso em momentos críticos da administração, como situações de calamidade, em que as respostas devem ser rápidas em função dos problemas apresentados e das cobranças realizadas pela imprensa e pela população, em geral.

Palavras-chave: Gestão pública, Automação de Sistemas. 


\section{ABSTRACT}

In this paper is presented a model of automation to be implemented in government departments, in order to streamline the procedures of the bureaucracy necessary to their achievement, contributing to a change of view of users regarding administrative delays disclosed. For this purpose, the objective of the model is to decrease the time between data collection, tabulation and decision-making by the public administrator. The automation concept used is shown by Cícero Couto de Moraes and Plínio Benedito de Lauro Castrucci, understanding the property of their adoption in public administration through the development process. The methodology presented proposes developing parallel and concurrent actions, even considering the serial manner in which they are carried out in the current administration, organized pyramid scheme. Moreover, the model is based on the implementation of a management system a database fed by several actors who carry out various activities in the process, dispensing with the formal signing of all documents and requiring only the identity of the electronic involved. Another difference is made possible accessibility to all employees involved, regardless of their level of education. This work presents the guiding directives of the model proposed automation and logistics deployment, citing the various existing and possible technologies to be applied in the automation of government services; exemplifies the possibility of automation in public administration with the work system deployed in Departamento de Edificações de São Paulo. The proposed methodology reveals the occurrence of significant reductions in time and final costs of the services performed, the reliability of results, quality of presentation of the final product in a standardized, mainly in the power management process that provides managers of all hierarchical levels. Another great advantage of the system is that it adapts to any work situation, be it technical or administrative, filing data from similar areas, where necessary, and providing results that can be used from top management to make it available to the public, by the Internet or through a situation room. In addition, automatic updating of data allows flexibility in possible course corrections, especially valuable aspect of the administration at critical moments, such as disaster situations, in which responses should be faster depending on the problems presented and the charges made by the

press and population in general.

Keywords: Public Management, Automation Systems. 


\section{LISTA DE FIGURAS}

Figura 1-1: Exemplos de redes sociais abertas disponíveis para usuários da internet

Figura 2-1: Primeiro escalão de uma secretaria da cidade de São Paulo.... 18

Figura 2-2: Organograma simplificado do Departamento de Edificações do Município de São Paulo...

Figura 2-3: Organograma simplificado da Companhia de Engenharia de Tráfego - CET da cidade de São Paulo................................................... 19

Figura 2-4: Fluxo verticalizado de informações ....................................... 21

Figura 2-5: Circulação simplificada e constante da informação entre os diversos níveis de atuação

22

Figura 4-1: Representação simplificada do fluxo de atividades para uma obra pública de engenharia na cidade de São Paulo.

Figura 4-2: Fluxograma das ações para abertura de um processo de obra na administração pública da cidade de São Paulo........................................... 32

Figura: 4-3: Fluxograma das ações para execução de um projeto na administração pública da cidade de São Paulo. 33

Figura 4-4: Fluxograma das ações do início da obra até uma medição na administração pública da cidade de São Paulo. 36

Figura 4-5: Fluxograma resumido das ações com a utilização da metodologia proposta.

Figura 4-6: Figura ilustrativa de diversos tipos de relatórios possíveis de serem executados com as informações contidas no banco de dados. 43

Figura 6-1: Figura ilustrativa do fluxo de informações coletados no campo e a tabulação no escritório 


\section{LISTA DE TABELAS}

Tabela 6-1: Quadro comparativo de tempos das atividades de diagnóstico das obras de manutenção dos prédios escolares.

Tabela 6-2: Quadro comparativo de tempos das atividades de diagnósticos com aprimoramento testado 


\section{SUMÁRIO}

1. AMBIENTAÇÃO DO PROBLEMA................................................. 14

2. INTRODUÇÃO AOS PRINCIPAIS ASPECTOS DA AUTOMAÇÃO DE SISTEMAS NA ADMINISTRAÇÃO PÚBLICA................................... 18

3. DIRETRIZES PARA A AUTOMAÇÃO DE SISTEMAS NA ADMINISTRAÇÃO PÚBLICA......................................................... 23

3.1 ANÁLISE DAS DIRETRIZES..................................................... 24

3.1.1 SEGURANÇA AO EXECUTOR...................................... 24

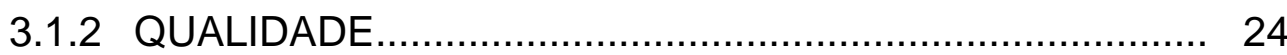

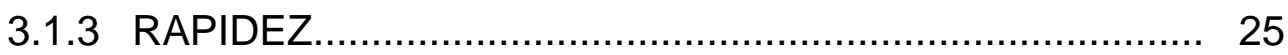

3.1.4 REDUÇÃO DE CUSTOS............................................... 26

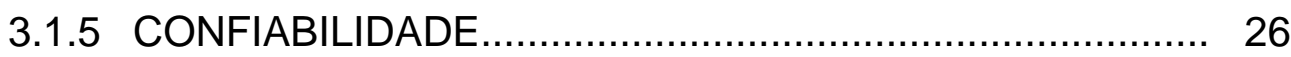

3.1.6 PODER DE GESTÃO..................................................... 27

4. A LOGÍSTICA DA AUTOMAÇÃO DE SISTEMAS NA ADMINISTRAÇÃO

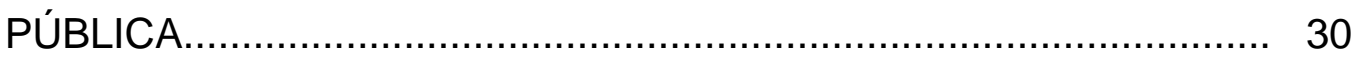

4.1 METODOLOGIA ATUAL DE TRABALHO.................................. 30

4.1.1 ABERTURA DO PROCESSO.......................................... 32

4.1.2 ELABORAÇÃO DO PROJETO.......................................... 32

4.1.3 ELABORAÇÃO DO CRONOGRAMA E DO ORÇAMENTO …….................................................... 33

4.1.4 PROCESSO LICITATÓRIO.............................................. 34

4.1.5 INÍCIO DA OBRA......................................................... 34

4.1.6 FISCALIZAÇÃO DA OBRA........................................... 35 
4.1.7 MEDIÇÃO DOS SERVIÇOS EXECUTADOS POR PERÍODOS

4.1.8 PAGAMENTOS DOS SERVIÇOS.................................... 35

4.1.9 RECBIMENTO DA OBRA ................................................ 36

4.2 METODOLOGIA PROPOSTA............................................... 36

4.2.1 INÍCIO DA NOVA METODOLOGIA................................. 37

4.2.2 SEQUÊNCIA DE ATIVIDADES...................................... 38

4.2.3 ATIVIDADES EXECUTADAS NA DIVISÃO DE OBRAS..... 41

4.2.4 QUESTIONÁRIO PRÉ-CONCEBIDO,,,,,,,,,,,,,,,,,,,,,,,,,,,,,,,,,,, 43

5. TECNOLOGIAS APLICADAS À AUTOMAÇÃO DE SISTEMAS NA ADMINISTRAÇÃO PÚBLICA......................................................... 45

5.1 TECNOLOGIAS APLICADAS À COLETA DE DADOS................ 45

5.1.1 DADOS ORIUNDOS DE PLANILHAS

PRÉ-CONCEBIDAS …..................................................... 45

5.1.2 DADOS ORIUNDOS DE INVENTÁRIOS PATRIMONIAIS... 46 5.2 TECNOLOGIAS APLICADAS À GESTÃO DE DADOS................ 46

6. MODELOS DE AUTOMAÇÃO DE SISTEMAS NA ADMINISTRAÇÃO PÚBLICA 48

6.1 PROJETO REFORMA ESCOLA DA PREFEITRUA NO MUNICÍPIO DE SÃO PAULO 48

6.1.1 IMPLANTAÇÃO INICIAL.............................................. 48

6.1.2 APRIMORAMENTO................................................ 50

6.1.3 CONSOLIDAÇÃO....................................................... 51

7. CONCLUSÕES/CONSIDERAÇÕES FINAIS.................................... 52 
8. REFERÊNCIAS BIBLIOGRÁFICAS............................................... 54

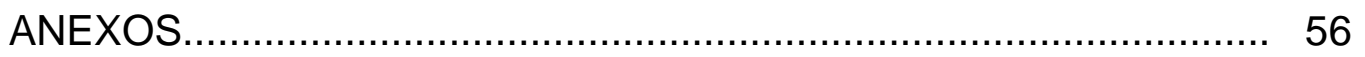




\section{AMBIENTAÇÃO DO PROBLEMA}

Historicamente a administração pública é considerada morosa em suas ações, o que corrobora para uma visão vigente da população sobre ser ela ineficiente e pagar proventos excessivamente altos a funcionários que não gostam do trabalho.

Tal visão exemplifica-se de várias maneiras, mas tomamos, aqui, a sátira musical feita em 1952 sobre "o modo de ver" a atuação do funcionário público. (Ver anexo I)

Mesmo recentemente, verificamos que a visão sobre a administração pública não mudou e este indicativo pode ser comprovado pelo resultado de uma pesquisa de opinião pública divulgada pelo jornal O Estado de São Paulo, em 20 de janeiro de 2011, onde se afirma: "Mais da metade da população não confia na administração pública" [1]; porém, ao se tomar conhecimento da rotina de trabalho do funcionalismo, nota-se que essa imagem é equivocada e que, muitas vezes, o servidor público trabalha com carga horária superior à do setor privado.

A dicotomia entre a visão construída e a realidade está na complexidade, diversidade e burocracia que envolvem a administração pública, principalmente em mega cidades como São Paulo. No caso da burocracia, em especial, grandemente vista como responsável pelos males administrativos, constitui-se ela em condição necessária para que os processos tenham conteúdo suficiente e satisfatório, tendo em vista as diversas auditorias impostas pelo Tribunal de Conta do Município (TCM) e pelo Ministério Público (MP); no entanto, sua importância nem sempre é reconhecida pelo cidadão, dada a morosidade que ela acarreta aos processos.

A morosidade administrativa ganhou maior evidência com o advento da informática e sua popularização, isto porque a população ganhou meios de conhecimento e cobrança mais eficazes através do acesso à internet e mesmo 
às informações em tempo real, através da imprensa. Dado que oposições a qualquer governo estabelecido são esperadas, independente de manifestações político-partidárias, a utilização de ferramentas da internet permitiu a troca de informações entre os cidadãos de todas as camadas sociais e de todos os níveis de instrução, possibilitando a troca e discussão de dúvidas, críticas e sugestões numa velocidade que, há poucos anos não era imaginável; criou-se, assim, a rede social, muito bem analisada por Manoel Castels em sua obra "A Sociedade em Rede" [2]. Neste trabalho Manoel Castels mostra que a tecnologia surgiu por meio do conhecimento adquirido pela humanidade e, hoje, o conhecimento é adquirido através desta tecnologia, embora, muitas vezes as informações obtidas não tenham um grau de comprovação adequado.

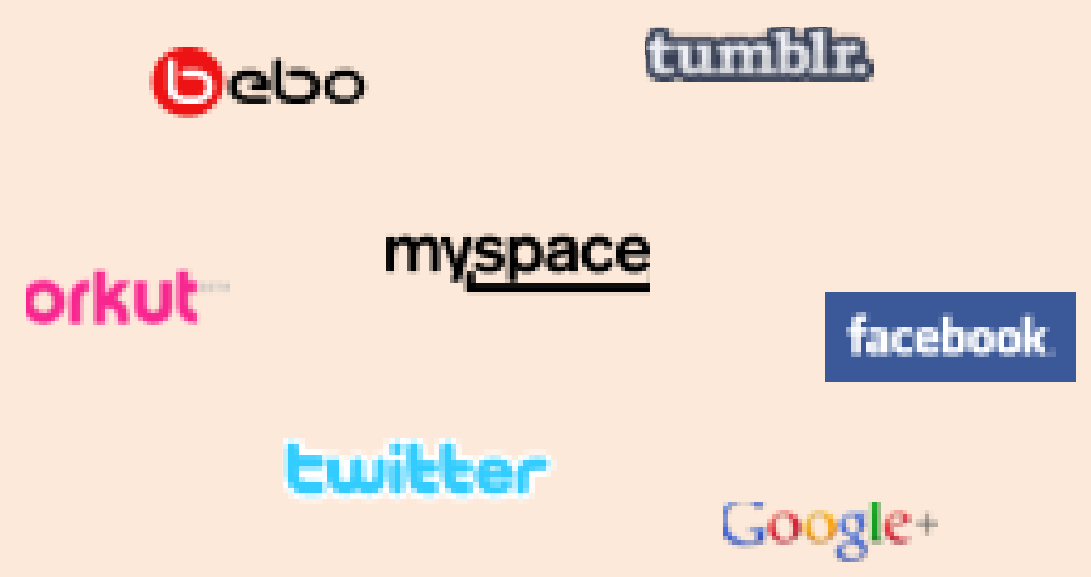

Figura 1-1: Exemplos de redes sociais abertas disponíveis para usuários da internet.

No caso do conhecimento que se refere ao relacionamento da população com a administração, há por vezes, o surgimento de propostas que, mesmo com coerência e bom conteúdo, são de difícil implantação quando analisadas pela ótica do administrador público.

Tais propostas são colocadas pela população como demandas imediatas e necessárias, mas, esbarram no programa de governo que é, normalmente, feito em época de campanha eleitoral e prevê sua implantação ao longo de quatro anos (exemplo disto é o disposto na Agenda 2012 que demonstra o programa de governo do município de São Paulo para o quadriênio 2009/2012). [3] 
Estas propostas, quando realmente necessárias, forçam alterações ou adaptações durante a vigência do mandato do governante, cujo novo rumo pode demorar meses (entre se detectar a necessidade de uma mudança, seja ela por motivos de anseio da população ou por motivos de calamidades, e o real início dos trabalhos), sendo que a cobrança da população pelas soluções é imediata.

Se na tomada de decisão das esferas mais altas do governo, em rápidas reuniões pode-se estabelecer a decisão de se proceder mudanças de rumo, na implantação destas medidas é que reside o problema.

A obtenção dos dados necessários para a elaboração dos projetos, alocação de recursos, licitação de obras, etc., requer esforços oriundos de diversos departamentos e setores, por vezes, de várias secretarias; assim, a burocracia da administração pública faz com que os prazos dos trabalhos fiquem dilatados.

Como é impossível para a administração eliminar a burocracia, e havendo situações reais em que a convivência de setores munidos de equipamentos e programas modernos com outros cuja defasagem chega ao obsoleto ou, mesmo, em que ocorre a inexistência do uso da informática no cotidiano do trabalho, a criação de meios eficazes para diminuí-la ou agilizá-la, através da automação dos sistemas nos órgãos públicos, é fator preponderante para o administrador moderno vencer as dificuldades impostas, tanto pela máquina administrativa quanto pelo anseio da população.

Para superar estas dificuldades e diante da impossibilidade de se parar a administração durante $\mathrm{o}$ processo de modernização dos sistemas e treinamento dos funcionários (cujo grau de conhecimento e familiarização com processo é totalmente desequilibrada), deve-se incorporar à administração mecanismos mais sofisticados que atuem nas diversas áreas da administração pública sem prejuízo da metodologia tradicional durante sua implantação. 
Diante do exposto, este trabalho apresenta uma proposta de automação em serviços da administração pública em que o principal enfoque está em procurar diminuir os efeitos da burocracia, com a agilidade necessária para vencer a morosidade da administração, buscando compatibilizar seu processo de implantação com a metodologia já em curso.

Outro dado importante é que a base do modelo deve ser tal que permita a acessibilidade de todos os funcionários independentemente de seu grau de instrução ou formação profissional. 


\section{INTRODUÇÃO AOS PRINCIPAIS ASPECTOS DA AUTOMAÇÃO DE SISTEMAS NA ADMINISTRAÇÃO PÚBLICA}

A estrutura organizacional da administração pública direta ou mesmo da indireta, em sua maioria, é tradicionalmente piramidal.

As secretarias, os departamentos, as superintendências e as empresas indiretas seguem, basicamente, o mesmo modelo de organograma conforme aparece na página oficial do governo do município de São Paulo. [4]

No caso municipal, uma secretaria é constituída, no topo da pirâmide, pelo Secretário; no primeiro escalão da administração estão os superintendentes, diretores de departamentos e os diretores das empresas indiretas, quando estas existirem, ainda de acordo com a página oficial do município de São Paulo. [4] (ver anexo II)

No segundo escalão temos os coordenadores, os diretores de divisões e os gerentes das empresas. Há poucas diferenças hierárquicas entre os componentes de uma ou outra secretaria.

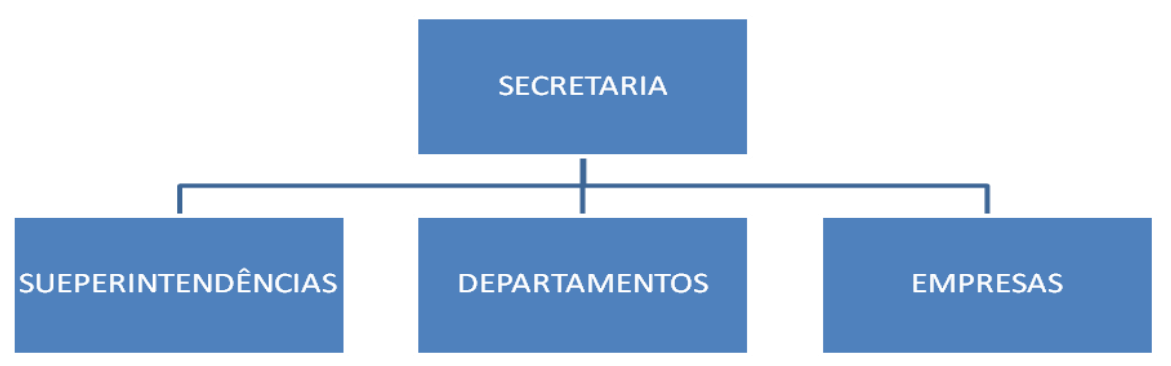

Figura 2-1: Primeiro escalão de uma secretaria da cidade de São Paulo

Se analisarmos um departamento típico da estrutura administrativa pública municipal também veremos esta mesma distribuição e teremos uma visão clara do sistema.

Tomemos, por exemplo, o Departamento de Edificações do Município de São Paulo. Montado através de dados da página oficial da Secretaria de 
Infraestrutura e Obras a sua estrutura organizacional pode ser representada pelo esquema abaixo. [5] (ver anexo III)

DIRETORIADE

DEPARTAMENTO

DIRETORIAS DE

DIVISÕES

\section{CHEFIAS DE SETORES}

Figura 2-2: Organograma simplificado do Departamento de Edificações do Município de São Paulo

Outro exemplo é extraído da página oficial da CET - Companhia de Engenharia de Tráfego. Esta é uma empresa da administração indireta, onde o mesmo padrão pode ser verificado. [6] (ver anexo IV)

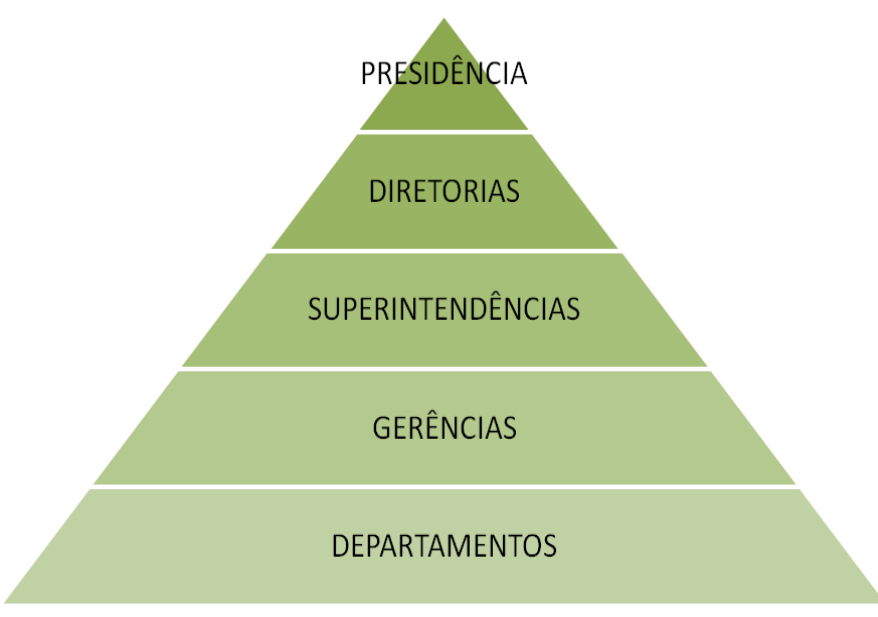

Figura 2-3: Organograma simplificado da Companhia de Engenharia de Tráfego - CET da cidade de São Paulo

Esta estrutura, embora de fácil controle, revela-se extremamente burocrática no dia a dia das atividades devido, principalmente, a seu aspecto formal. 
A interação entre estes agrupamentos é, basicamente, feita de forma serial com trâmite de documentos indo e vindo por meio de despachos contidos em processos.

Existe a troca de informações realizada de maneira informal entre os técnicos envolvidos das diversas áreas, mas, na maioria das vezes, não de forma que o assunto tratado seja considerado de acordo com a prioridade estabelecida pelo plano de governo para cada secretaria envolvida.

Nos assuntos prioritários, entendimentos entre chefias são realizados para agilizar os serviços. Esses entendimentos, embora úteis, nem sempre se traduzem na eficiência desejada.

Esta situação ocorre, principalmente, pela característica dos serviços realizados nas diversas áreas envolvidas em que o gestor do programa não tem o conhecimento técnico específico de cada área e nem os tempos necessários para sua realização.

Isso faz com que o principal gestor de um programa fique sem a real noção dos prazos finais para os diversos serviços do programa de governo, o que induz a tomada de decisões baseadas em tempos de realização que não correspondem à realidade.

Outro fator de elevada importância é o fluxo de informações, regra geral, não ocorrer de forma matricial. Muitas decisões podem ser tomadas sem a necessidade de circulação documental entre as esferas de gestão, não decisões estratégicas, mas, as decisões técnicas que, juntas, montam as atividades. 


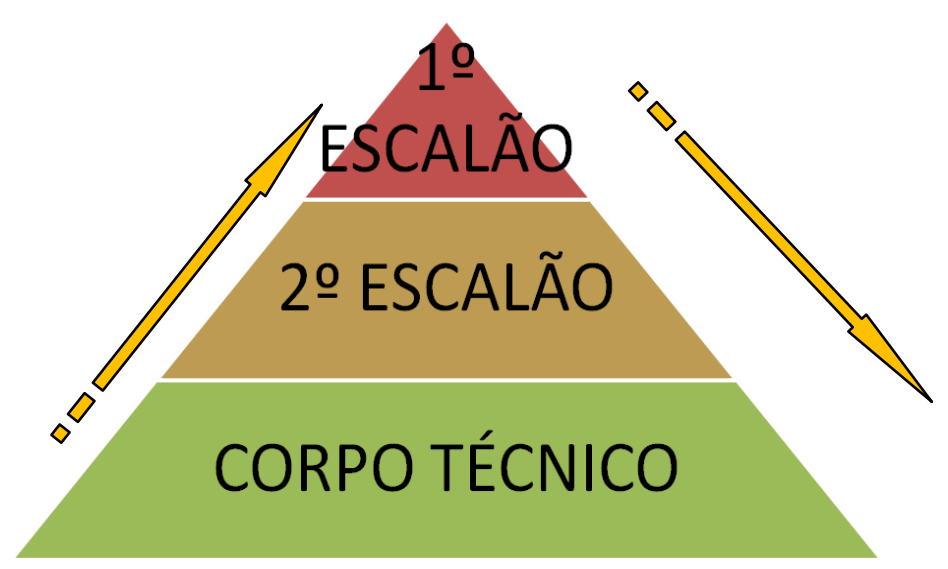

Figura 2-4: Fluxo verticalizado de informações

$\mathrm{Na}$ maioria das vezes, decisões meramente técnicas e ainda na fase de estruturação da atividade, apresentam uma grande demora em seu processo de evolução em função do tempo gasto pelo trâmite do processo saindo do corpo técnico, alcançando os escalões superiores e novamente voltando para o corpo técnico.

Muitas vezes esse trâmite é totalmente desnecessário bastando para isso que os altos escalões tenham uma ferramenta que possibilite uma gestão do processo sem a necessidade de tramitação ou mesmo de uma aprovação formal nos documentos.

A falta dessa ferramenta, em alguns casos, é suprida pela informalidade que, se de um lado otimiza as decisões, de outro, não permite que a totalidade do histórico das ações seja preservado para futuras consultas ou debates.

Há, também, um fator relevante a ser considerado, que é a falta de conhecimento do sistema como um todo. O que existe é um conhecimento limitado, basicamente, ao trabalho do funcionário, não indo muito além de um setor ou departamento.

A automação de sistemas na administração pública visa à introdução de ferramentas que permitam aos gestores, dos mais variados níveis do organograma, ter uma visão do andamento do processo sem uma necessidade 
de intervenção direta e, também, uma clareza dos resultados alcançados nas diversas fases do processo.

Essas ferramentas podem ser de uso individual na medida em que tornam automática uma série de procedimentos repetitivos ou coletiva, quando a tabulação de determinados serviços são disponibilizados a vários profissionais, de forma homogênea, imediatamente após sua realização e validação na origem.

De maneira simplificada, na figura 2.5 temos o uso de ferramentas que, de forma contínua, possibilitam à alta gestão acompanhar todo o processo.

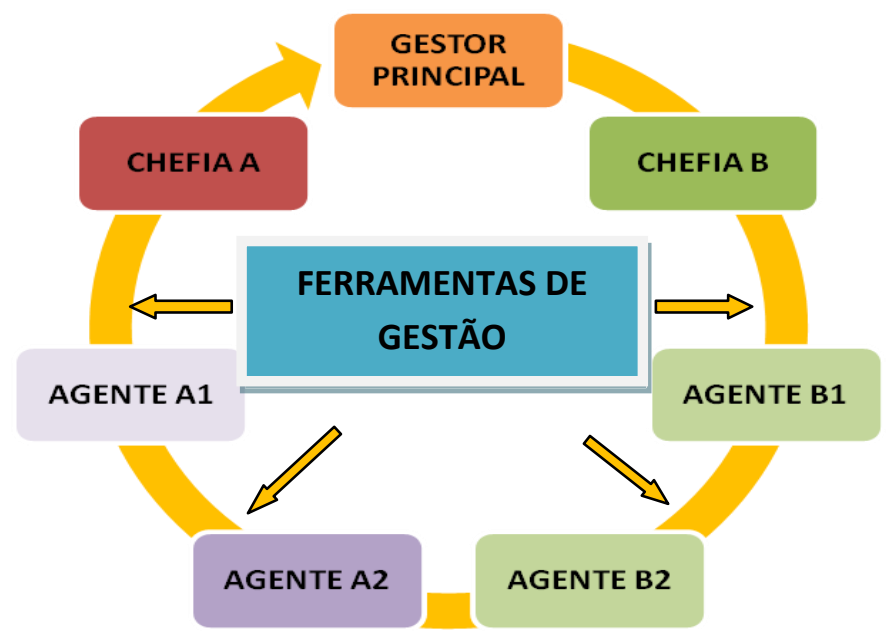

Figura 2-5: Circulação simplificada e constante da informação entre os diversos níveis de atuação 


\section{DIRETRIZES PARA A AUTOMAÇÃO DE SISTEMAS NA ADMINISTRAÇÃO PÚBLICA}

Neste capítulo serão apresentadas as diretrizes que norteiam a introdução de automações de sistemas na administração pública.

A ideia imediata que se tem de automação envolve o princípio adotado nas indústrias e que nos leva a visualizar uma série de equipamentos realizando tarefas antes executadas pelos trabalhadores, ou mesmo, a execução de serviços gerais para os quais o ser humano não tem capacidade de realização em virtude das suas limitações.

Tomemos a definição de automação descrita pelos professores Cícero Couto de Moraes e Plínio Benedito de Lauro Castrucci:

"Entende-se por automação qualquer sistema, apoiado em
computadores, que substitua o trabalho humano em favor da
segurança das pessoas, da qualidade dos produtos, da rapidez
da produção ou da redução de custos, assim aperfeiçoando os
complexos objetivos das indústrias e dos serviços. Exemplos:
automação da mineração, da manufatura metálica, dos
grandes processos químicos contínuos, automação bancária,
metroviária, aeroportuária". [6]

Numa análise rápida desta definição, realmente tem-se a impressão da ideia comum de que automação só se faz na cadeia produtiva, porém, se aprofundarmos o conceito veremos que, ao introduzirmos a automação de sistemas na administração pública estaremos, também, satisfazendo aos princípios nela descritos.

Parte dos serviços da administração pública nada tem a ver com equipamentos automatizados, mas com processos que podem ser, parcialmente ou em sua totalidade, alvos de estudos visando sua automação trazendo, dessa maneira, segurança ao executor, qualidade, rapidez e redução de custos nos serviços.

Além de atender a todos esses princípios, um projeto de automação na administração pública deve ver acrescentada a confiabilidade no sistema e o poder de gestão que as informações adquiridas devem contemplar. 
São estas as principais diretrizes norteadoras de tal projeto.

\subsection{ANÁLISE DAS DIRETRIZES}

\subsubsection{SEGURANÇA AO EXECUTOR.}

A automação dos serviços na administração pública deve levar em conta a segurança do executor na realização dos serviços de rotina. Muitos deles ocorrem em situações adversas que requerem operações potencialmente perigosas.

É o caso da fiscalização de obras, operações de trânsito, etc. Atualmente temos condições de automatizar muitos destes serviços eliminando-se a necessidade do agente permanecer em áreas de risco por tempo prolongado ou mesmo em tempo integral.

A utilização de equipamentos remotos para leituras de dados e sua consequente integração a um sistema gestor georreferenciado permite que 0 agente possa fiscalizar a perfeita execução das tarefas ou mesmo realizar a verificação da integridade de um patrimônio público sem a necessidade de estar próximo ou presente no local do item analisado.

\subsubsection{QUALIDADE.}

A qualidade na implantação de sistemas automatizados tem, como principal parâmetro, a comparação com o resultado atingido pelo mesmo serviço quando executado por métodos tradicionais. Tal avaliação pode levar em conta diferentes fatores. Um deles diz respeito à possibilidade de erro.

Evidentemente que, ao se automatizar um serviço, procura-se eliminar tal ocorrência comum na execução do mesmo serviço de forma manual.

Isto é conseguido atribuindo-se grau de tolerância para que os resultados a serem atingidos fiquem contidos na faixa plausível de erro. Por meio da 
automação, essa faixa de erro tende a ser menor.

Outro fator importante em sistemas automatizados é que se permite um critério de validação dos serviços. Essa validação pode atingir vários níveis hierárquicos antes de o serviço ser aprovado para uso.

A padronização do resultado também é fator relevante. Diferentemente do processo manual, em que a apresentação do produto final fica sob a responsabilidade do agente executor (e, com isso, sujeita ao seu grau de discernimento quanto ao que é mais importante relatar), na automação do sistema produzem-se relatórios pré-concebidos em que constam todos os itens necessários e com disposição gráfica padronizada.

A execução de diversas formas de relatórios finais, com a utilização de filtros, permite atingir os diversos níveis hierárquicos da administração de maneiras diferenciadas, pois o acesso às informações é compatibilizado com as demandas e formas de atuação de cada nível.

\subsubsection{RAPIDEZ.}

A eliminação do trâmite excessivo de informações no processo de projetos em curso já proporciona uma rapidez no trato do assunto em questão, mas, a possibilidade de acesso aos dados imediatamente após sua obtenção é o que, efetivamente, faz do processo uma ferramenta veloz.

Esta condição é conseguida por meio da integração dos dados de diversos programas, tabelas e imagens, que, após serem inseridas no programa gestor, automaticamente produzem relatórios ou outros agrupamentos de informações que permitem a diversos usuários realizarem serviços cujos dados precisam ser compartilhados entre si. Além disto, a desnecessária burocracia de tramitação e despachos, que nada acrescenta de novidade ao processo em si, pode ser evitada pela inclusão de determinado documento relativo ao serviço e necessário para a construção do processo físico, não virtual, somente a partir do resultado final de cada etapa do trabalho. 
Outro item importante que se obtém com a adoção de um sistema automatizado é a possibilidade de um assunto ser tratado de forma paralela nos diversos setores evitando-se, quando possível, o trabalho de forma serial, cujo formato não permite uma melhor gestão do tempo.

\subsubsection{REDUÇÃO DE CUSTOS.}

Um item sempre presente na gestão de um processo é o seu custo. Cabe ao gestor a análise dos valores econômicos para garantir que o resultado final fique dentro do planejado.

O sistema automatizado permite que o resultado dos trabalhos executados por funcionário ou grupo deles fique armazenado em um banco de dados e disponibilizado para todos os demais, guardadas as possibilidades de acesso, em função dos diversos níveis e cargos.

Isto elimina a execução dos serviços em duplicidade e, dessa maneira, minimiza diretamente o custo final do serviço.

Outro fator preponderante é que, com a otimização do tempo em função da eliminação da burocracia excessiva e da execução dos relatórios finais de forma automatizada e padronizada, o sistema amplia a disponibilidade do funcionário para atender outras demandas e, também, facilita a execução completa de uma agenda de trabalho.

\subsubsection{CONFIABILIDADE.}

Em todos os níveis hierárquicos da administração pública a confiança de que um determinado serviço executado seja diretamente ligado ao seu executor é um dos fatores preponderantes para sua aceitação. A cobrança de responsabilidades ultrapassa o período de uma gestão podendo ser questionada vários anos após seu término.

Num sistema automatizado, dado que a coleta de dados é feita por 
equipamentos munidos de GPS, fica garantida a precisa localização no mapa da cidade do serviço prestado e o horário em que foi realizado.

A confiabilidade do sistema está garantida pela assinatura eletrônica de cada funcionário que participa dos trabalhos.

Com esta assinatura eletrônica de cada trabalho elaborado por qualquer funcionário será garantida a total confiabilidade e segurança de que este não poderá ser modificado por outra pessoa, qualquer que seja seu nível hierárquico, pois o original ficará preservado e sempre disponível no banco de dados.

Se alguma alteração for executada num arquivo do banco de dados, automaticamente esta alteração receberá uma nova assinatura eletrônica, contendo a data, hora e o executor da alteração ou elaboração do novo trabalho.

Uma das maiores preocupações dos agentes públicos é essa garantia autoral, pois, se há conviç̧ão na qualidade do produto por ele executado, não há a mesma convicção de que a utilização destes dados seja feita da maneira planejada no início dos trabalhos. O sistema automatizado permite a comparação dos dados iniciais coletados com o resultado final obtido, ambos vinculados a seus respectivos autores.

\subsubsection{PODER DE GESTÃO.}

A existência de gestores de vários níveis em um processo é que permite sua execução de acordo com sua programação inicial e, também, possibilita a correção de rumo, caso necessária.

Um dos fatores mais positivos na adoção de um sistema de automatização na administração pública é a gestão dos resultados e a gestão dos recursos alocados para as diversas tarefas.

Como toda sistemática de trabalho, a partir da validação dos serviços, todas as 
atividades têm seu local de execução, data, hora e executor identificados. Num sistema automatizado, em tempo real, os gestores de todos os níveis terão oportunidade de acompanhar o desenrolar dos serviços e, na medida da necessidade, corrigir possíveis distorções.

Este poder de gestão é conseguido por meio de ferramentas gráficas, fotografias digitais, filmes, tabelas de dados técnicos, contábeis e financeiros que automaticamente são atualizados.

Apresentações em reuniões técnicas ou mesmo de divulgação dos serviços terão suporte, caso o gestor assim o desejar, baseadas em dados que permitem a tomada de decisões com garantia total de atualização.

Com relação à gestão, uma conduta interessante foi adotada no Departamento de Edificações do Município de São Paulo (EDIF) com o uso da ferramenta de automação, denominada Rede de Petri, muito utilizada em sistemas industriais e totalmente desconhecida na gestão de sistemas administrativos.

Com algumas adaptações foi possível delinear, por completo, o percurso das atividades necessárias para a execução de uma obra realizada pelo Departamento.

Notava-se que, a partir da emissão de um documento ou trabalho realizado por um profissional ou por um setor, a cobrança pelo resultado final era imediata, não sendo clara a quantidade de serviços necessários e seus respectivos tempos de realização.

Inicialmente, para equacionar o problema foi encomendado um estudo que possibilitasse o mapeamento total do processo.

Este estudo teve, como resultado, um fluxograma (ver anexo V) que esclarecia, por completo, todas as ações, nomeava seus executores e indicava seus devidos tempos de duração.

O fluxograma apresentado tinha todas as informações necessárias para se acompanhar o processo, mas, as diversas formações e capacitações dos 
funcionários envolvidos, desde Secretários até os técnicos executores dos trabalhos, fez com que ele não fosse entendido e, por isso, relegado a um papel secundário. Assim, as cobranças continuaram a ocorrer como de costume.

A utilização de uma adaptação da Rede de Petri deu uma visão clara do posicionamento de cada participante no processo, bem como, esclareceu para todos os envolvidos o momento correto para as eventuais cobranças. (ver anexo $\mathrm{VI})$ 


\section{A LOGÍSTICA DA AUTOMAÇÃO DE SISTEMAS NA ADMINISTRAÇÃO PÚBLICA}

Neste capítulo será apresentada, inicialmente, a logística de atuação em vigor nos sistemas da administração pública. A seguir, é proposta uma nova metodologia de ação, calcada na automação do processo.

\subsection{METODOLOGIA ATUAL DE TRABALHO}

Os serviços na administração pública podem ser executados:

a) Por funcionários públicos concursados;

b) Funcionários contratados por empresas mistas, sob regime da CLT;

c) Empresas privadas contratadas por meio de processo licitatório em suas diversas modalidades.

Não importa quem execute o serviço, o comum em todos é a coleta de dados necessários para a realização da atividade, sejam dados de engenharia, financeiros, contábeis ou administrativos.

A logística do sistema proposto começa por essa coleta.

Em se tratando de obras de engenharia, a elaboração dos serviços compete à Secretaria Municipal de Infraestrutura e Obras (SIURB), por meio de suas superintendências, departamentos e empresas. [3]

O presente trabalho dará ênfase à execução das atividades exercidas pelo Departamento de Edificações (EDIF) [4] da Secretaria Municipal de Infraestrutura e Obras da cidade de São Paulo (SIURB). [3]

Ao analisarmos a sistemática de trabalho de uma obra pública de engenharia temos uma sequência de atividades, considerando como já definida a obra a ser executada. São elas:

1. Abertura do processo;

2. Elaboração do projeto;

3. Elaboração do cronograma e do orçamento;

4. Licitação da obra;

5. Início da obra;

6. Fiscalização da obra; 
7. Medições dos serviços executados por períodos;

8. Pagamentos dos serviços;

9. Recebimento da obra

Nesta listagem, diversas atividades aparecem agrupadas em itens representativos. Ao longo do trabalho muitas delas serão retomadas e explicadas mais detalhadamente.

Na figura 4.1, temos uma representação do fluxo das atividades mencionadas.

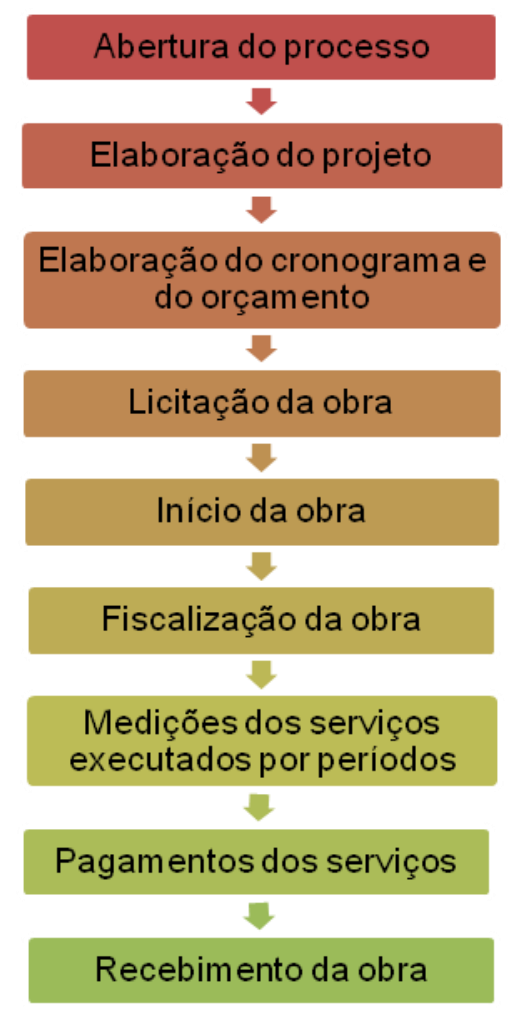

Fig. 4.1: Representação simplificada do fluxo de atividades para realização uma obra pública de engenharia na cidade de São Paulo.

Como pode ser visto, todo o processo caminha de forma serial, embora algumas atividades, durante sua execução, possam desenvolver serviços de forma paralela. 


\subsubsection{ABERTURA DO PROCESSO}

Toda obra na administração pública começa com a abertura de um processo.

Normalmente o órgão demandante remete ao executante um ofício solicitando o início do processo de execução. Feito isso, é solicitado um número para o processo que acompanhará a execução da obra do início até o seu término.

Todos os procedimentos e documentos gerados pela demanda serão colocados neste processo. Algumas vezes, devido à complexidade do empreendimento poderá ser aberto novo processo, que, sempre será referendado ao processo inicial e o acompanhará até ao final dos trabalhos.

O fluxograma desta atividade é representado na figura 4.2.

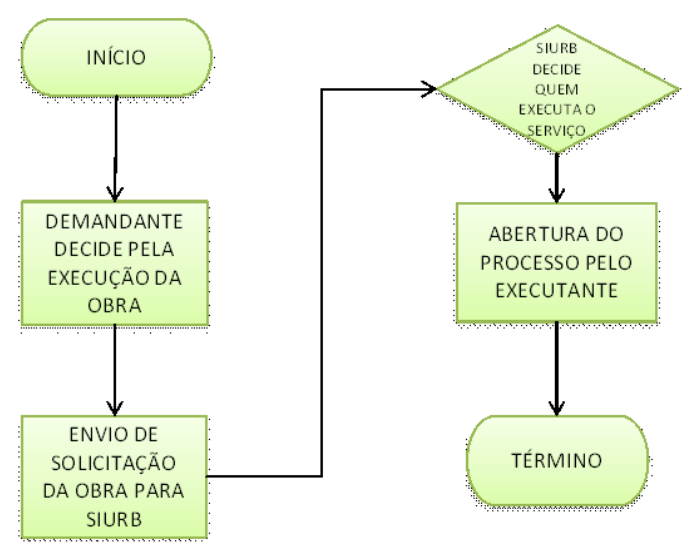

Fig. 4.2: Fluxograma das ações para abertura de um processo de obra na administração pública da cidade de São Paulo.

\subsubsection{ELABORAÇÃO DO PROJETO}

Antes mesmo da elaboração do projeto propriamente dito, algumas etapas deverão ser contempladas como a necessidade de se identificar o terreno; só após esta identificação, com o devido acordo do órgão demandante, poderá ser iniciado o projeto.

Com a definição das necessidades oferecidas pelo demandante da obra (Secretaria Municipal da Educação [SME]; Secretaria Municipal da Cultura [SMC]; etc.) procura-se um projeto padrão que os atenda ou então, faz-se necessária a elaboração de um projeto novo. 
Caso se optar por um projeto padrão, as adaptações necessárias poderão ser executadas por funcionários do próprio departamento ou por contratação de empresas projetistas por meio de alguma modalidade prevista na Lei de Licitações (lei 8.666) [7]. Se for necessário um novo projeto, a sistemática será a mesma.

Em paralelo à execução do projeto, ocorrem outras ações, como o trâmite, nos diversos órgãos envolvidos, de toda a documentação para liberação do terreno, seja ele de propriedade da municipalidade ou de terceiros.

Outra ação é a execução da sondagem com parecer do tipo de fundação a ser executada.

Também é possível, à medida que o projeto básico esteja definido, contratar a elaboração de um projeto de implantação da obra dentro das características do terreno escolhido.
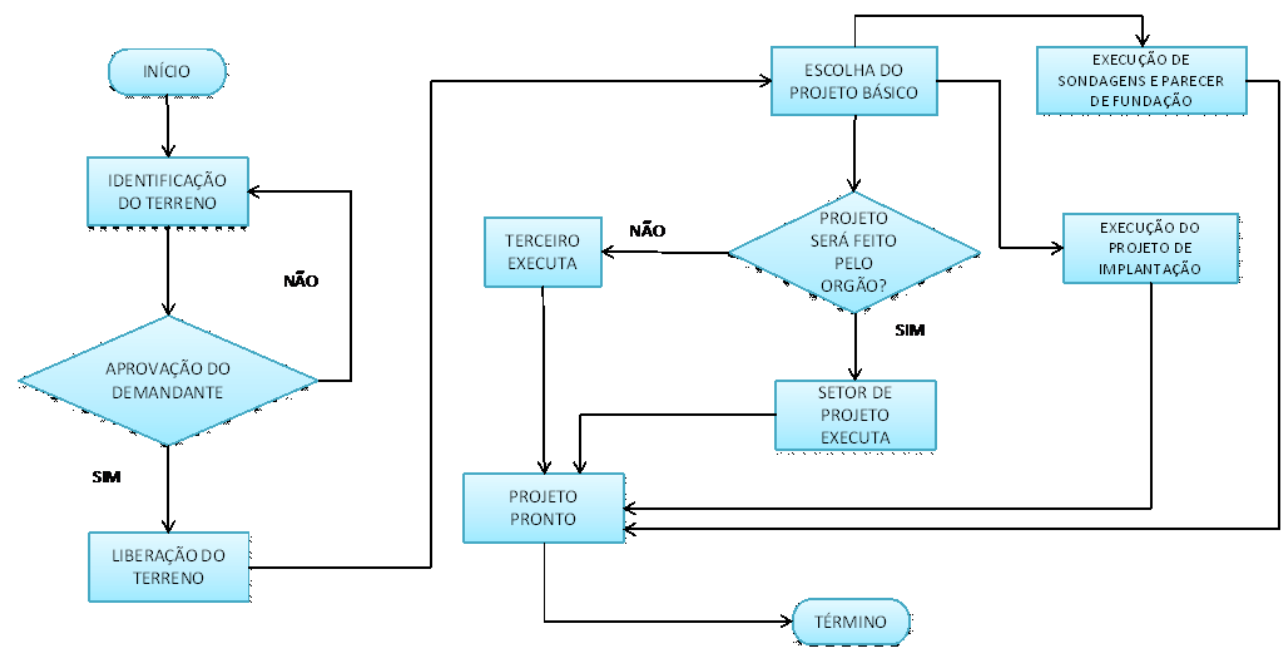

Fig. 4.3: Fluxograma das ações para execução de um projeto na administração pública da cidade de São Paulo.

\subsubsection{ELABORAÇÃO DO CRONOGRAMA E DO ORÇAMENTO}

Com o recebimento do projeto pela Divisão de Projetos e realizados todos os procedimentos de possíveis correções o projeto é enviado à Divisão de Orçamentos. 
De posse dos quantitativos contidos no projeto e da indicação do local onde será efetuada a obra, são realizadas as planilhas de preços unitários de todos os serviços necessários para a conclusão do empreendimento.

Estes preços são referenciais e adotados a partir das Tabelas de Preços Unitários da Secretaria de Infraestrutura e Obras (SIURB) e do Departamento de Edificações do Município de São Paulo (EDIF) [8].

Caso algum serviço não conste nestas tabelas, são realizadas composições específicas para eles.

Com os valores referenciais já determinados, são definidos o cronograma físico-financeiro e o termo de referência de todos os serviços que compõem a obra sendo, assim, possível o início do processo licitatório.

\subsubsection{PROCESSO LICITATÓRIO}

O setor de licitação da Secretaria de Infraestrutura e Obras (SIURB) [4] do município é responsável por todo o processo licitatório, que segue a Lei de Licitação ํㅜ 8.666 [7] em suas diversas modalidades.

Evidentemente quanto mais complexa é a obra, tanto mais demorado será o processo licitatório, mas, em linhas gerais não havendo nenhum problema de ordem jurídica ou mesmo contestação do Tribunal de Contas do Município (TCM), uma licitação demora de dois a quatro meses para ser completada, já com adjudicação e homologação do vencedor.

\subsubsection{INÍCIO DA OBRA}

Após todos os itens descritos terem sido concretizados é dada a Ordem de Início para que a empresa ganhadora comece a execução dos serviços.

A Ordem de Início é um documento que propicia a realização de todos os eventos futuros do empreendimento, sem ela a etapa de materialização do projeto no campo não é permitida e a partir dela é que todos os itens contratuais estarão relacionados. 


\subsubsection{FISCALIZAÇÃO DA OBRA}

Com o início dos serviços diversos procedimentos serão realizados e, de acordo com o sistema atual, a maioria deles será realizada em série.

De posse do projeto referente à obra, a fiscalização acompanha cada etapa dos serviços por meio de visitas ao local, elaborando relatórios técnicos que serão arquivados no processo referente à obra, para futuras consultas e auditorias.

\subsubsection{MEDIÇÃO DOS SERVIÇOS EXECUTADOS POR PERÍODOS.}

Decorrido um determinado período, geralmente um mês, as medições do que foi realizado neste tempo será atestada e encaminhada para pagamento.

Normalmente este processo gera situações adversas, tanto para a fiscalização quanto para a empresa executora. Isso ocorre em virtude do acompanhamento das obras não ser feito por meio de um banco de dados gerenciável e, sim, por arquivos de documentos feitos pela empreiteira e pelo órgão fiscalizador, que não são padronizados.

Com isso, a perda de tempo entre a elaboração do documento inicial e do documento final entregue para os setores contábil e financeiro é enorme, ocorrendo, normalmente, uma situação de conflito entre contratante e contratado.

\subsubsection{PAGAMENTOS DOS SERVIÇOS}

Para se efetuar o pagamento dos serviços executados no período medido, além dos documentos técnicos elaborados pela Divisão de Obras, existe a necessidade de se anexar outros documentos de ordem contábil exigidos por legislação.

Somente após toda a documentação ser entregue e verificada pelo setor de contabilidade é que a medição pode ir para o setor financeiro para ser efetuado o pagamento à empreiteira.

Os atrasos nesta parte do processo também são uma constante, na maioria das vezes ocasionados por problemas relacionados à própria empresa prestadora dos serviços que, não mantém suas documentações atualizadas. 


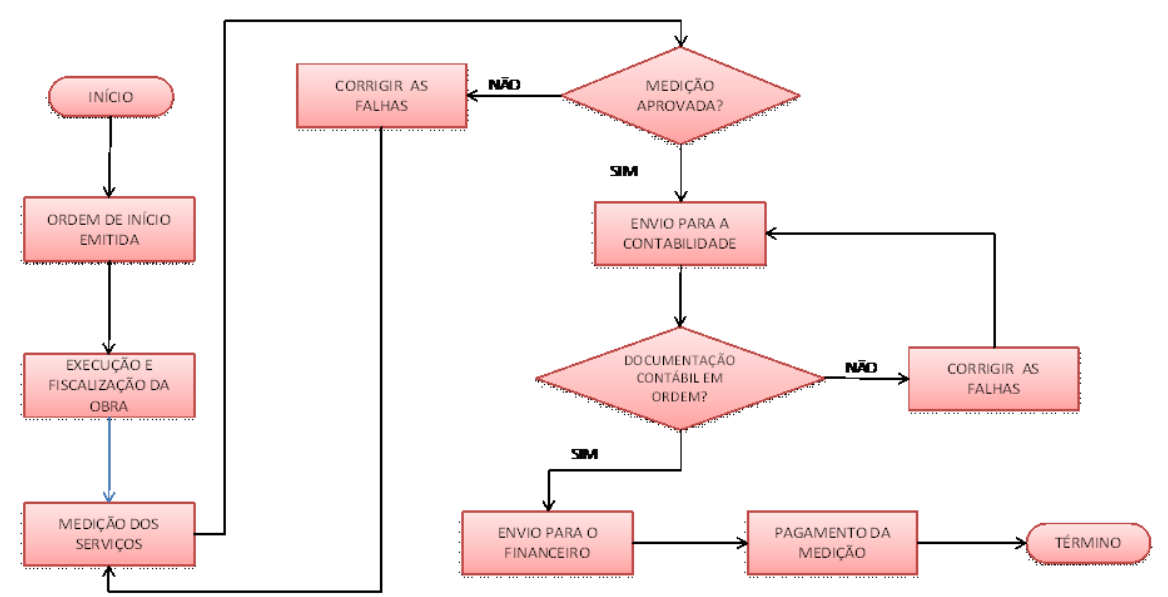

Fig. 4.4: Fluxograma das ações do início da obra até uma medição na administração pública da cidade de São Paulo.

\subsubsection{RECEBIMENTO DA OBRA}

As ações descritas no item anterior serão repetidas pelos períodos determinados pelo cronograma da obra até a realização dos serviços complementares, executados ao término do empreendimento.

Atrasos são constantes, quer por situações provocadas pela própria administração pública, quer por problemas relacionados pela empreiteira executora dos serviços.

Quaisquer destes problemas são documentados e fazem parte do processo referente à obra, mas esta documentação fica somente disponível em cópias de papel ou mesmo arquivos eletrônicos cujo âmbito de consulta está restrito ao setor de trabalho em que ocorre.

Vencidos todos os trâmites e entregue a obra, será elaborada a medição final dos serviços e feito o recebimento provisório do empreendimento, sendo que, o recebimento definitivo será emitido, em média, seis meses após sua entrega.

\subsection{METODOLOGIA PROPOSTA.}

Do descrito no item anterior, percebe-se, claramente, que a execução das atividades segue trajetória serial, mesmo que muitas delas possam ocorrer de forma paralela, pois, não são pré-requisitos para outros serviços. 
A metodologia proposta neste trabalho baseia-se na implantação de um sistema de gestão de um banco de dados alimentado pelos diversos atores que exercem as mais variadas atividades do processo.

É condição primária que esse sistema gestor reconheça todos os aplicativos utilizados pelos profissionais da administração pública; ou seja, o que existe e é utilizado como aplicativo de apoio às tarefas (não importando sua fabricação e seu nível de atualização) deverá ser reconhecido com validação dos seus dados.

Outro fator importante é que a implantação deste novo sistema deverá ocorrer de modo que a administração não tenha uma parada no seu funcionamento, ou seja, os dois sistemas, o atual e o proposto, têm que conviver de maneira harmônica até a total migração do velho para o novo.

\subsubsection{INÍCIO DA NOVA METODOLOGIA}

O início da metodologia proposta dá-se a partir da abertura do arquivo no banco de dados, com sua nomeação seguindo o mesmo número do processo aberto pelo sistema tradicional.

Com isto, todos os futuros documentos, dados ou relatórios serão armazenados nesse arquivo.

O resultado das consultas ou da gestão da informação será conseguido por meio da interação dos dados existentes no arquivo e referentes ao mesmo processo.

Desta maneira, o primeiro documento a ser arquivado será a solicitação de abertura do processo.

A partir daí, todos os trabalhos realizados pelos diversos agentes envolvidos na execução do processo aberto serão armazenados neste arquivo; muitos deles ainda seguirão o caminho serial, ou seja, não poderão ter início antes da elaboração de outro serviço, tido como pré-requisito; muitos outros, porém, serão executados em paralelo, desde que seus pré-requisitos sejam comuns.

Todos os trabalhos elaborados, em qualquer tipo de aplicativo, deverão ser armazenados no banco de dados que deverá ter a capacidade de fazer as interações necessárias para promover a gestão dos resultados. 


\subsubsection{SEQUÊNCIA DE ATIVIDADES.}

A sequência de atividades será descrita a seguir, de forma que se obtenha um entendimento da racionalização da linha de trabalho a ser implantada.

Partindo-se do exposto no capítulo 3, propõem-se atividades em paralelo, buscando subsídios, no próprio banco de dados, em trabalhos já armazenados e cujos novos resultados serão novamente disponibilizados assim que estiverem completos.

Muitas atividades dos setores envolvidos não precisarão aguardar todo 0 término dos trabalhos de outros setores para serem implementadas; à medida que etapas forem concluídas e disponibilizadas no banco de dados, elas poderão ser base execução de trabalhos por outros profissionais.

Evidente que estes trabalhos, para serem inseridos no banco de dados, deverão ter todas as aprovações hierárquicas de cada setor de origem. Também, nesta metodologia, não há necessidade da assinatura formal em todos os documentos; basta a identidade eletrônica dos envolvidos.

$\mathrm{Na}$ figura 4.5, está representado o fluxograma resumido do grupo de ações necessárias para se iniciar e terminar um empreendimento no Departamento de Edificações do Município de São Paulo (EDIF) [4].

Muitas atividades e serviços foram omitidos tentando-se reduzir em atividades fins. Inúmeras atividades secundárias devem ser realizadas e todos os produtos gerados deverão ser armazenados no banco de dados, no endereço correspondente ao empreendimento, para que todos os envolvidos tenham possibilidade de conhecimento, de acordo com os níveis de acessibilidade permitida.

À exceção das atividades exercidas pela Divisão de Obras do Departamento de Edificações do Município de São Paulo (EDIF), todas as outras são realizadas em ambiente interno do Departamento, utilizando-se, em sua totalidade, aplicativos comuns de mercado, tais como: digitadores de textos, planilhas eletrônicas, programas de computação gráfica (amplamente utilizados em escritórios de projetos), programas para apresentações em reuniões, etc.

Esta metodologia aproveita, em sua totalidade, os recursos existentes e utilizados pelos funcionários que participam do processo havendo, apenas, a necessidade da criação de procedimentos para a apresentação dos resultados dos trabalhos em formatos padrões que fiquem disponibilizados no banco de 
dados e cujo acesso permita o início imediato de uma nova tarefa, com coleta automática dos dados necessários para seu desenvolvimento.

Tais formatos, também, devem permitir a interação de todos os dados dos diversos arquivos que estão armazenados no programa gestor de forma a permitir a elaboração de planilhas e outras ferramentas gerenciais para 0 alto escalão hierárquico do Departamento de Edificações. 


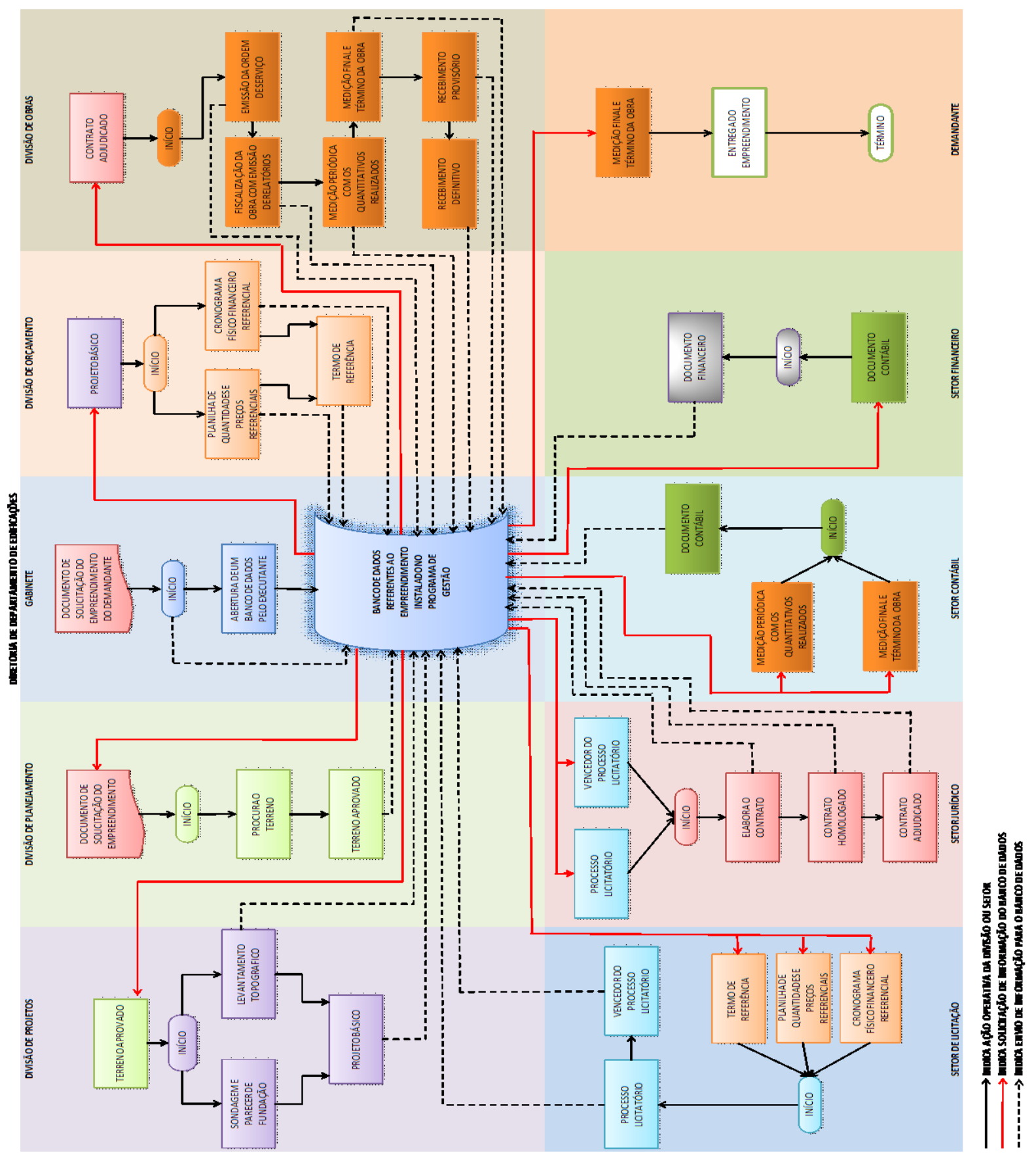

Fig. 4.5: Fluxograma resumido das ações com a utilização da metodologia proposta. 


\subsubsection{ATIVIDADES EXECUTADAS NA DIVISÃO DE OBRAS.}

Neste item será feita uma análise mais aprofundada das atividades exercidas pelos profissionais da Divisão de Obras e citadas nos itens 5.1.6 e 5.1.7. Nesta nova metodologia elas deverão sofrer mudanças na execução dos seus procedimentos de trabalho.

A rotina de um engenheiro fiscal de obras pode ser traçada conforme a lista apresentada a seguir:

1) Deslocamento até o local da obra.

2) Fiscalização dos diversos serviços executados pela empreiteira executante da obra.

3) Análise dos resultados dos ensaios laboratoriais dos diversos materiais empregados.

4) Captura de fotos necessárias para realização dos relatórios de obras.

5) Análise dos quantitativos apresentados dos serviços realizados.

6) Análise do cronograma da obra - o previsto e o realizado.

7) Deslocamento até o escritório central.

8) Realização de relatórios das visitas para o arquivo da Divisão de Obras.

9) Execução do relatório de medição do período correspondente.

Cada obra tem suas características e complexidades. Desta maneira, algumas análises poderão ter um grau de dificuldade maior do que outras e, para não se perder o histórico, os relatórios das atividades mais complexas devem ser realizados de imediato, para não se omitir nenhum pormenor, seja ele técnico ou administrativo, fato que pode ocorrer no intervalo entre uma e outra visita feita pelo fiscal da obra.

Isto demanda um tempo maior no escritório para a execução do relatório, o que poderá acarretar atrasos nas visitas em outras obras nas quais o profissional também realiza fiscalização.

Estas ocorrências são comuns e produzem efeitos danosos tanto para a administração quanto para a empresa executante, cujas medições poderão sofrer atrasos.

A principal mudança de procedimentos vem com a introdução de equipamentos modernos e remotos para coleta de dados. 
O coletor de dados será a nova ferramenta do fiscal de obras e é com ele que todas as atividades serão realizadas de forma simples, direta e rápida.

Num só equipamento estarão disponibilizadas para o fiscal de obras todas as ferramentas necessárias para a execução de suas tarefas. Nele estará contido um telefone remoto, um capturador de imagens, um GPS (Global Positioning System) [9] e, também, um questionário pré-concebido com todos os itens de rotina que deverão ser fiscalizados.

Basicamente, serão executadas todas as atividades citadas no início deste item, mas de forma automática, com imediata disponibilização no banco de dados e com a possibilidade de apresentação em inúmeros modelos de relatórios, cada qual atendendo às necessidades do usuário em seus setores de trabalho.

Outro fator importante que se deve salientar é a economia de tempo despendido para a realização das tarefas, proporcionando a racionalização dos serviços de fiscalização. No capítulo 6 serão apresentados os comparativos de tempo gastos para realização de um trabalho pelo sistema atual e pelo automatizado.

O mencionado questionário é composto de perguntas cujas possíveis respostas são induzidas e, basicamente, atingem todos os possíveis estágios em que se encontra a obra no momento da realização da fiscalização. Possíveis respostas ou mesmo perguntas não contempladas pelo questionário poderão ser acrescentadas a ele no momento da execução da fiscalização.

A introdução de anexos fotográficos, filmes digitais ou qualquer outro tipo de documento também é prevista neste modelo e sua introdução dar-se-á pelo aparelho coletor no momento da realização da fiscalização, ou mesmo após. Uma vez coletados e validados os dados referentes aos serviços de determinada visita do fiscal à obra, eles são inseridos nos diversos relatórios mencionados.

$\mathrm{Na}$ figura, temos alguns exemplos dos inúmeros relatórios possíveis de serem criados com o uso interativo das informações contidas no banco de dados. 


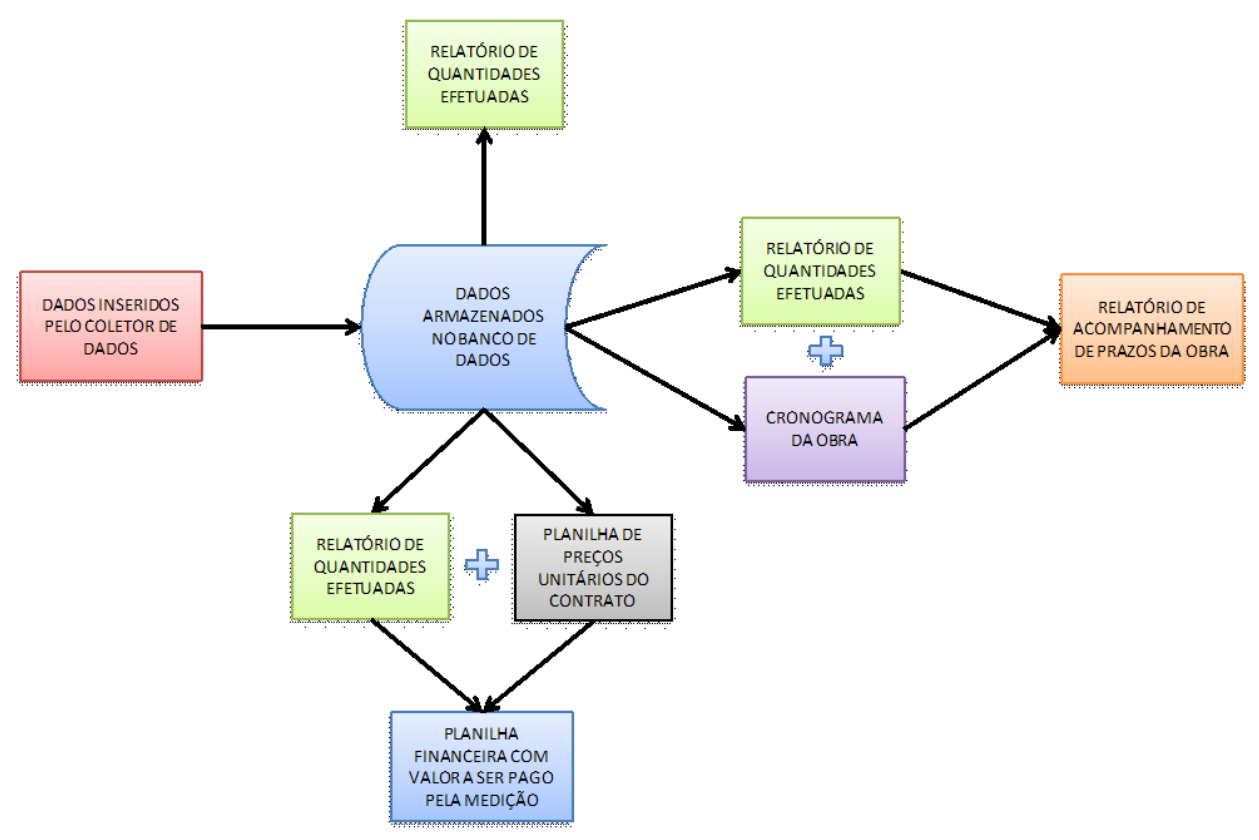

Fig. 4.6: Figura ilustrativa de diversos tipos de relatórios possíveis de serem criados com as informações contidas no banco de dados.

\subsubsection{QUESTIONÁRIO PRÉ-CONCEBIDO.}

Nesta metodologia, o cadastro dos itens referentes a uma determinada obra que não sofrerão mudanças desde seu início até seu final deverá ser feito e suas informações disponibilizadas no banco de dados para aproveitamento em todos os relatórios desenvolvidos.

Outro item importante é a disponibilidade de planta georeferenciada da cidade para o posicionamento da obra por meio de suas coordenadas.

Além destes itens citados, outros que forem julgados importantes também deverão estar disponibilizados no questionário.

Um exemplo deste questionário é o que foi elaborado para uso na EMURB (Empresa Municipal de Urbanização) em que havia a necessidade de se fazer diagnóstico dos problemas encontrados nas escolas de Ensino Fundamental (EMEF) e de Ensino Infantil (EMEI) no âmbito da Secretaria Municipal de Educação de São Paulo (SME) [3].

Este trabalho ficou conhecido com Reforma Escola e teve seu acesso permitido à população por meio da página oficial do município com o link "Reforma Escola" [3]. 
A opção por uma automação no sistema deveu-se à necessidade de uma grande quantidade de visitas, o que tornou inviável o processo tradicional de análises.

A constituição do questionário foi simples, porém abrangente, e todos os possíveis problemas foram listados; no caso de detecção de algum problema novo, ele, imediatamente era inserido.

No ANEXO VII, temos as gravuras ilustrativas de todos os passos préconcebidos de uma visita para diagnósticos introduzidos no relatório.

Neste exemplo, a duração total do diagnóstico foi de 2,86 minutos, enquanto que, se fosse realizado pelos padrões atuais, considerando somente o tempo efetivo gasto entre o início do diagnóstico e a execução do relatório final, seria de 95,3 minutos, aí incluso o tempo médio de deslocamento do local ao escritório para a realização do relatório (tempo médio de 60 minutos). O tempo de execução foi 33,3 vezes menor, usando o método automatizado.

Um dos fatores preponderantes nesta metodologia é que a elaboração do questionário deverá ser minuciosa, com análise profunda dos técnicos responsáveis pelas respostas, para que a totalidade dos itens analisados seja contemplada, evitando-se possível perda de eficiência no processo.

O tempo de diagnóstico aumentará se a complexidade exigida na atividade for maior, mas, sempre haverá um ganho de eficiência na modalidade proposta se o questionário for bem realizado. 


\section{TECNOLOGIAS APLICADAS À AUTOMAÇÃO DE SISTEMAS NA ADMINISTRAÇÃO PÚBLICA}

A utilização do sistema proposto baseia-se em tecnologias cujo avanço na área da informática permitiu a associação de ferramentas modernas com conceitos já consagrados que, por limitantes tecnológicos ou financeiros, não eram possíveis de serem aplicados.

Serão citadas as diversas tecnologias existentes e possíveis de serem aplicadas na automação dos serviços da administração pública. É importante salientar que não faz parte deste trabalho a apresentação de detalhes técnicos das tecnologias associadas ao sistema proposto.

\subsection{TECNOLOGIAS APLICADAS À COLETA DE DADOS}

A inclusão das informações que abastecerão o banco de dados é feita por maneiras distintas e por diversos programas.

Se os dados forem gerados internamente e através dos programas de uso rotineiro na administração, tais como:

- planilhas eletrônicas (Excel ou similares) [10];

- processadores de textos (Word ou similares) [11];

- programas para projetos por computador (AutoCAD ou similares) [12];

- programas de engenharia por computador (MSProject ou similares)[13]; as entradas dar-se-ão diretamente dos computadores dos usuários, após a validação pelos superiores hierárquicos estabelecidos no processo.

Se os dados forem gerados externamente poderá haver situações distintas, descritas a seguir.

\subsubsection{DADOS ORIUNDOS DE PLANILHAS PRÉ-CONCEBIDAS.}

O acesso às planilhas dar-se-á de diversas maneiras como, por exemplo, com a utilização de notebook ou mesmo computadores conectados à internet.

A utilização destes equipamentos reduzirá, sobremaneira, a versatilidade do sistema implantado, mas, não inviabilizará seu emprego. 
O ideal, para se atingir a performance descrita neste trabalho é a utilização de PDAs (Personal Digital Assistants) [14] cuja grande capacidade computacional permite executar diversas funções, que vão desde a telefonia celular até a utilização de programas para várias áreas de interesse.

A comunicação entre estes dispositivos móveis e a retaguarda deverá atender ao padrão de transmissão de dados da tecnologia celular GSM (Groupe Special Mobile) [15], podendo ser realizada usando os seguintes protocolos:

- GPRS (General Packet Radio Service) [15]

- EDGE (Enhaneed Data Rates for GSM Evolution) [15]

- HSDPA (High Speed Dowlink Packet Access) [16]

- ou outros, que venham a substituir ou melhorar os acima listados.

\subsubsection{DADOS ORIUNDOS DE INVENTÁRIOS PATRIMONIAIS}

Para a gestão de bens patrimoniais, sejam eles imobiliários ou mobiliários urbanos, o sistema de automação na administração pública pode utilizar os coletores de dados (PDA) [14] associados à implantação de identificação dos bens por meio de TAG (etiquetas eletrônicas) [17] e um sistema RFID (Radio Frequency Identification) [18] que se comunicam enviando informações via software para o banco de dados central.

Os coletores podem ser portáteis (PDA) [14]. Quanto às informações contidas nos TAGs [17], também poderão ser coletadas por meio de antenas instaladas em viaturas que, através de radio frequência, varrerão as vias da cidade, coletando os dados automaticamente.

\subsection{TECNOLOGIAS APLICADAS À GESTÃO DE DADOS}

A gestão dos dados compreende várias funções e aspectos iniciando-se com o recebimento dos dados oriundos dos diversos meios de coleta. Seus sistemas operacionais devem atender aos requisitos do padrão POSIX (Portable Operating System Interface for Computer Environment) [19].

O servidor do sistema deve ter capacidade de, além deste recebimento, enviar dados aos coletores de dados em campo; controlar a utilização do sistema pelos usuários; controlar suas senhas de acesso; controlar todas as operações efetuadas realizando o registro de cada uma; armazenar os dados das atividades executadas; armazenar as imagens capturadas; integrar todas as 
informações ao Sistema de Informações Geográficas [20] já em uso no município.

$\mathrm{Na}$ constituição do banco de dados deve ser previsto que futuras reconfigurações necessárias, devido às ampliações como: o acréscimo de coletores de dados, acréscimos de funções de campo, etc., não interfiram nos demais dados já configurados.

Sua capacidade de armazenamento e disponibilidade das informações deve ser prevista de modo a garantir uma trabalhabilidade segura e flexível garantindo a velocidade que se espera do sistema. 


\section{MODELO DE AUTOMAÇÃO DE SISTEMAS NA ADMINISTRAÇÃO PÚBLICA.}

Neste capítulo será analisado um exemplo de automação de sistemas na administração pública.

\subsection{PROJETO REFORMA ESCOLA DA PREFEITURA NO MUNICÍPIO DE SÃO PAULO. [21]}

\subsubsection{IMPLANTAÇÃO INICIAL.}

O exemplo citado no item 4.2.4 foi implantado pela EMURB (Empresa Municipal de Urbanização). Inicialmente a automação do processo foi de uma forma simplificada, visto que, a tecnologia disponível no seu inicio, ainda era incipiente.

Desta forma, implantou-se um processo de automação que associava equipamentos e programas existentes à época [22].

Dispunha-se de computadores portáteis, câmeras digitais, conectores remotos para transmissões (via internet), computadores e um programa gestor funcionando como agregador das informações e também como banco de dados.

A sistemática utilizada foi de montarem-se dois grupos de trabalho: um, externo, que realizaria os trabalhos de coleta de dados e outro, interno, que analisaria os dados coletados e montaria os relatórios.

Os dados levantados seriam enviados via internet, através dos conectores remotos, e compunham-se de relatório descritivo feito em processador de texto e fotos digitais capturadas pelas câmeras e enviadas como arquivos de imagem.

No escritório central, a equipe interna receberia os relatórios e as fotos e montaria um relatório final padronizado, disponibilizando-o no banco de dados para utilização dos interessados; no caso, Secretaria Municipal de Educação (SME) e Secretaria Municipal de Infraestrutura e Obras (SIURB). 
Assim, muitas etapas de um procedimento de diagnóstico foram eliminadas ou tiveram seu tempo reduzido permitindo que uma equipe reduzida conseguisse um resultado muito satisfatório, com o cumprimento perfeito do cronograma.

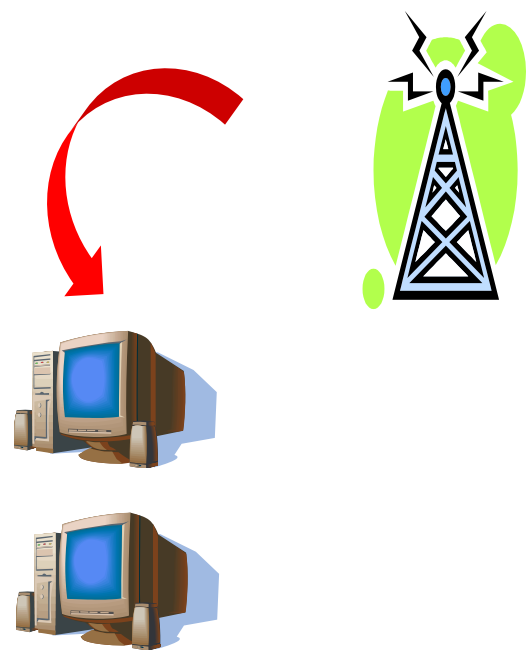

Escritório
Campo

Fig. 6.1: Figura ilustrativa do fluxo de informações coletados no campo e a tabulação no escritório

Com tempos levantados a partir de trabalhos realizados pelos dois métodos, agrupando-se todas as atividades em itens abrangentes, conseguiu-se uma redução no tempo de 3,4 vezes com a adoção do novo método.

A tabela 6.1 apresenta a comparação de tempo dos dois modelos de trabalho. Este comparativo foi realizado no início dos trabalhos do programa de manutenção dos prédios escolares, em 2007. 


\begin{tabular}{|c|c|c|}
\hline ATIVIDADES NECESSÁRIAS PARA O DIAGNÓSTICO & \begin{tabular}{|c|} 
TRADICIONAL \\
DURAÇÃO HORAS \\
\end{tabular} & \begin{tabular}{|c|} 
IDEALIZADO \\
DURAÇÃO HORAS
\end{tabular} \\
\hline Preparação de mapas e roteiros para vistorias. & 2 & 1 \\
\hline $\begin{array}{l}\text { O responsável se desloca até a sede para obter os mapas e roteiros } \\
\text { em que serão realizadas as vistorias. }\end{array}$ & 2 & 0 \\
\hline $\begin{array}{l}\text { O responsável se desloca até os pontos de parada agendadas para } \\
\text { realizar as vistorias. }\end{array}$ & 1 & 1 \\
\hline $\begin{array}{l}\text { O responsável anota em papel as ocorrências e as fotografas em cada } \\
\text { ponto de parada. }\end{array}$ & 6 & 2,5 \\
\hline $\begin{array}{l}\text { O responsável descarrega as fotos em um computador e digita o } \\
\text { relatório anexando as fotos. }\end{array}$ & 3 & 0,5 \\
\hline O responsável envia o relatório a seu supervisor. & 1 & 0 \\
\hline $\begin{array}{l}\text { O supervisor distribui os relatórios para que o demandante, de acordo } \\
\text { com as competências e urgências, envie ao executor das obras. }\end{array}$ & 2 & 0 \\
\hline TOTAL DE HORAS TRABALHADAS & 17 & 5 \\
\hline
\end{tabular}

Tabela 6.1: Quadro comparativo de tempos das atividades de diagnóstico das obras de manutenção dos prédios escolares.

Esta sistemática permitiu avanços consideráveis em relação ao tempo e também provocou alterações no modo de trabalho até então empregado.

As equipes externas não precisavam se encaminhar ao escritório central para o início de suas atividades diárias partindo diretamente de seus lares para os locais de execução dos diagnósticos.

Tal fato, associado a uma logística de distribuição dos locais levando em consideração a região de moradia dos técnicos, permitiu uma racionalização de custos, pois os profissionais não precisavam se dirigir até o escritório central, enfrentando as dificuldades do trânsito e, muitas vezes, a restrição de circulação imposta pelo rodízio em dias definidos em função dos números das placas dos automóveis.

\subsubsection{APRIMORAMENTO.}

Nos últimos meses do contrato citado, evoluiu-se para um aprimoramento do sistema estudando-se a implantação do modelo citado no item 4.2.4 que, nos testes, apresentou uma performance sensivelmente melhor com a adoção do questionário pré-concebido.

A tabela 6.2 mostra o comparativo de tempo entre a execução tradicional e a automatizada. 


\begin{tabular}{|c|c|c|}
\hline ATIVIDADES NECESSÁRIAS PARA O DIAGNÓSTICO & \begin{tabular}{|c|} 
TRADICIONAL \\
DURACÃOHORAS
\end{tabular} & \begin{tabular}{|c|} 
IDEALIZADO \\
DIRAC̃̃OHORAS
\end{tabular} \\
\hline Preparação de mapas e roteiros para vistorias. & 2 & 1 \\
\hline $\begin{array}{l}\text { O responsável se desloca até a sede para obter os mapas e roteiros } \\
\text { em que serão realizadas as vistorias. }\end{array}$ & 2 & 0 \\
\hline $\begin{array}{l}\text { O responsável se desloca até os pontos de parada agendadas para } \\
\text { realizar as vistorias. }\end{array}$ & 1 & 1 \\
\hline $\begin{array}{l}\text { O responsável anota em papel as ocorrências e as fotografas em cada } \\
\text { ponto de parada. }\end{array}$ & 6 & 0 \\
\hline $\begin{array}{l}\text { O responsável descarrega as fotos em um computador e digita o } \\
\text { relatório anexando as fotos. }\end{array}$ & 3 & 0 \\
\hline O responsável realiza a vistoria & 0 & 0,1 \\
\hline O responsável envia o relatório a seu supervisor. & 1 & 0 \\
\hline $\begin{array}{l}\text { O supervisor distribui os relatórios para que o demandante, de acordo } \\
\text { com as competências e urgências, envie ao executor das obras. }\end{array}$ & 2 & 0 \\
\hline TOTAL DE HORAS TRABALHADAS & 17 & 2,1 \\
\hline
\end{tabular}

Tabela 6.2: Quadro comparativo de tempos das atividades de diagnóstico com aprimoramento implantado.

Com este aprimoramento, a racionalização proporcionou uma nova redução no tempo na ordem de oito vezes em relação ao procedimento original em que a automação não era aplicada.

Esta redução foi constatada levando-se em conta a duração média de uma vistoria num estabelecimento de ensino e, também, tomando-se a vistoria como totalmente realizada e não como mostrada pontualmente no item 4.2.4.

\subsubsection{CONSOLIDAÇÃO.}

Se a implantação efetiva da melhoria, com adoção de questionário préconcebido, não pôde ser totalmente utilizada no contrato de vistorias e diagnóstico das escolas devido ao término das atividades, ela serviu de base para um novo contrato firmado, em que a EMURB necessitava de um inventário de todos os pontos de ônibus existentes na cidade.

Um novo questionário foi pré-concebido, atendendo à nova demanda e o cadastramento teve início com o georeferenciamento de todos os pontos de ônibus, diagnóstico por tipologia estrutural, estado de conservação, serviços necessários para sua manutenção e fotos do local.

Outras demandas foram sendo criadas em função desta automação e, atualmente o sistema está totalmente consolidado. 


\section{CONCLUSÕES.}

A administração pública tem peculiaridades como qualquer outro setor e, evidentemente, uma alteração nos procedimentos de trabalho acarreta resistências.

Foi assim na implantação do modelo de automação adotado inicialmente na EMURB no projeto Reforma Escola, e assim também será, quando implementado em qualquer setor da administração.

As resistências originam-se por diferentes motivos: desde a insegurança do funcionário em relação ao seu futuro, até a total repulsa ao novo método em função do desconhecimento do uso de tecnologias avançadas e totalmente inovadoras.

Cabe ao gestor destes programas o discernimento de providenciar o treinamento necessário e abrangente de modo a solucionar todas as questões relativas às dúvidas dos funcionários que irão participar destes trabalhos automatizados.

A experiência alcançada com as implantações já feitas tem provado que, à medida que a metodologia vai se tornando conhecida, as desconfianças vão ficando cada vez mais raras, até sua plena aceitação por parte dos funcionários.

Novas dinâmicas deverão ser implantadas para que os resultados de um setor possam, automaticamente, ser utilizados por outros setores com a padronização de relatórios utilizando-se, o máximo possível, de ferramentas da informática que propiciem o intercâmbio de dados, sem a necessidade de retrabalho.

O resultado dessa metodologia testada é amplamente favorável com reduções consideráveis nos prazos de execução, nos custos finais dos serviços executados, na confiabilidade dos resultados, na qualidade da apresentação do produto final de forma padronizada e principalmente no poder de gestão que 0 processo propicia aos gestores de todos os níveis hierárquicos.

Os custos de implantação destes sistemas tendem, à medida que estes se massificam, a atingir patamares cada vez mais baixos, permitindo que quaisquer órgãos, mesmo com poucos recursos, possam ter acesso a esta tecnologia. 
Outra grande vantagem do sistema é que ele se adapta a qualquer situação de trabalho, seja ela técnica ou administrativa, interpondo dados de áreas afins sempre que necessário e proporcionando resultados que podem ser utilizados desde a gestão superior até sua disponibilização para a população, via Internet.

Dados estatísticos podem ser automaticamente atualizados, não necessitando mais de preparos antecipados; as reuniões de avaliação do desempenho das atividades podem ser realizadas com informações conseguidas em tempo real, possibilitando correções de rumo imediatas.

Tais ações são de grande valia em momentos críticos da administração, principalmente em casos de calamidade, em que as respostas devem ser rápidas em função dos problemas apresentados e das cobranças realizadas pela imprensa e pela população, em geral. 


\section{REFERÊNCIAS BIBLIOGRÁFICAS}

[1] Mais da metade dos paulistanos não confia na administração pública. Disponível em: http://estadao.com.br/busca/satisfação\%20publica. Acesso em 20/01/2011.

[2] Agenda 2012 - Programa de metas da cidade de São Paulo. São Paulo: Lu Fernandes Edit., 2012.

[3] Secretarias. Disponível em:

http://www.capital.sp.gov.br/portalpmsp/homec.jsp. Acesso em 26/01/2011.

[4] EDIF. Disponível em:

http://www.prefeitura.sp.gov.br/cidade/secretarias/infraestrutura. Acesso em 27/12/2010

[5] Informações institucionais - organograma: http://www.cetsp.com.br. Acesso em 18/08/2011

[6] MORAES, C. C.; CASTRUCCI, P. L. Engenharia de automação industrial. 2 ed. Rio de Janeiro : LTC, 2007.

[7] IBRAP. Lei no 8.666/93, completa, revista e atualizada, Instituto Brasileiro de Administração Pública, IBRAP. 10. ed. Ribeirão Petro: IBRAP, 2010.

[8] Tabela de Custos.

http://www.prefeitura.sp.gov.br/cidade/secretarias/infraestrutura. Acesso em 27/12/2009.

[9] KENNEDY, M. The global positioning system and GIS. Ann Arbor: Taylor and Francis., 2002.

[10] MORAZ, Eduardo. Curso essencial de Excel. São Paulo: Digerati Books., 2006.

[11] PIMENTEL, Alex. Word 2007 - Curso prático. São Paulo: Digerati Books., 2008.

[12] ROQUEMAR, Baldam; COSTA, Lourenço. Autocad 2009 - Utilizando totalmente. São Paulo: Editora Etica., 2008. 
[13] BORGES, Elizabeth; POSSI, Marcus. MSProject 2007 - Novos recursos para apoio ao controle de projetos. São Paulo: Editora Ciência Moderna., 2007.

[14] Applying RFID Hand-Held Device for Factory Equipment Diagnosis - Kai-Ying Cheng, Yu-Huei Liao and Fan-Chih Tien - departamento of Industrial Engineering and Mangement National Taipei - University of Technology, Taipei, Taiwan, R.O.C. - In: IEEE Internacional Conference on Systems, Man and Cybernetics, San Antonio, TX - USA - fls 1209-1210, october.:2009.

[15] SVERZUT, José Umberto. GSM, EPRS, EDGE e UMTS - Evolução a caminho da terceira geração (3G). São Paulo: Ed. Érica.:2005.

[16] Study on Network Architecture for Traffic Information Collection Systems bsed on RFID Technology - Mijeon Kim, Jinsoo Park, Jaeyong Oh, Hakjin Chong, Yoonkee Kim - Future Technology Laboratory, KT - In: IEEE Asia-Pacific Services Computing Conference - fl 63. 2008.

[17] Applying RFID Hand-Held Device for Factory Equipment Diagnosis - Kai-Ying Cheng, Yu-Huei Liao and Fan-Chih Tien - departamento of Industrial Engineering and Mangement National Taipei - University of Technology, Taipei, Taiwan, R.O.C. - In: IEEE Internacional Conference on Systems, Man and Cybernetics, San Antonio, TX USA - fls 1209, october.:2009.

[18] GARFINKEL, Simson; ROSEMBERG, Beth. Aplications security and privacy. Ed. Addison Wesley.,2005.

[19] Information Technology - Portable Operating Sustem Interface (POSIX) - Base Specifications, Issue 7 - ISSO/IEC/IEEE9945 - Chapter 2.,2009.

[20] São Paulo, uma cidade digital. Disponível em: http://www.prefeitura.sp.gov.br/cidade/secretarias/planejamento/prodam/ . Acesso em 9/10/2009.

[21] VENDRAMIN, V. L. Utilização de tecnologia de informação para gestão de dados no serviço público - estudo de caso. 48 p. Trabalho de Conclusão de Curso de Pós-Graduação em Gestão Pública. Apresentado a Fundação Escola de Sociologia e Política de São Paulo, 2009.

[22] VENDRAMIN, V. L.; DIAS, E. M. The modernization of the public service using information techinology. WSEAS TRANSACTIONS on SYSTEMS and CONTROL. v. 5, n.7, p. 519-528, July 2010. ISSN: 1991-8763. 
ANEXOS 
ANEXO I - Letra da Marchinha de Carnaval "Maria Candelária" 
ANEXO I - Letra da Marchinha de Carnaval "Maria Candelária"

Composição de Armando Cavalcanti e Klecius Caldas (1952)

Transcrição obtida através do site

http://letras.terra.com.br/armando-cavalcanti/1513172 em 07/10/2011.

"Maria Candelária,

É alta funcionária,

Saltou de paraquedas,

Caiu na letra "O", oh, oh, oh, oh,

Começa ao meio dia,

Coitada da Maria,

Trabalha, trabalha, trabalha de fazer dó,

Oh, oh, oh, oh,

A uma vai ao dentista,

As duas vai ao café,

As três vai ao modista,

As quatro assina o ponto e dá no pé,

Que grande vigarista que ela é". 
ANEXO II - Organograma da Secretaria de Infraestrutura Urbana e Obras do Município de São Paulo. 
ANEXO II - Organograma da Secretaria de Infraestrutura Urbana e Obras do Município de São Paulo.

Organograma montado a partir das informações contidas no site oficial do município, link "SIURB - Secretaria de Infraestrutura Urbana e Obras do Município de São Paulo".

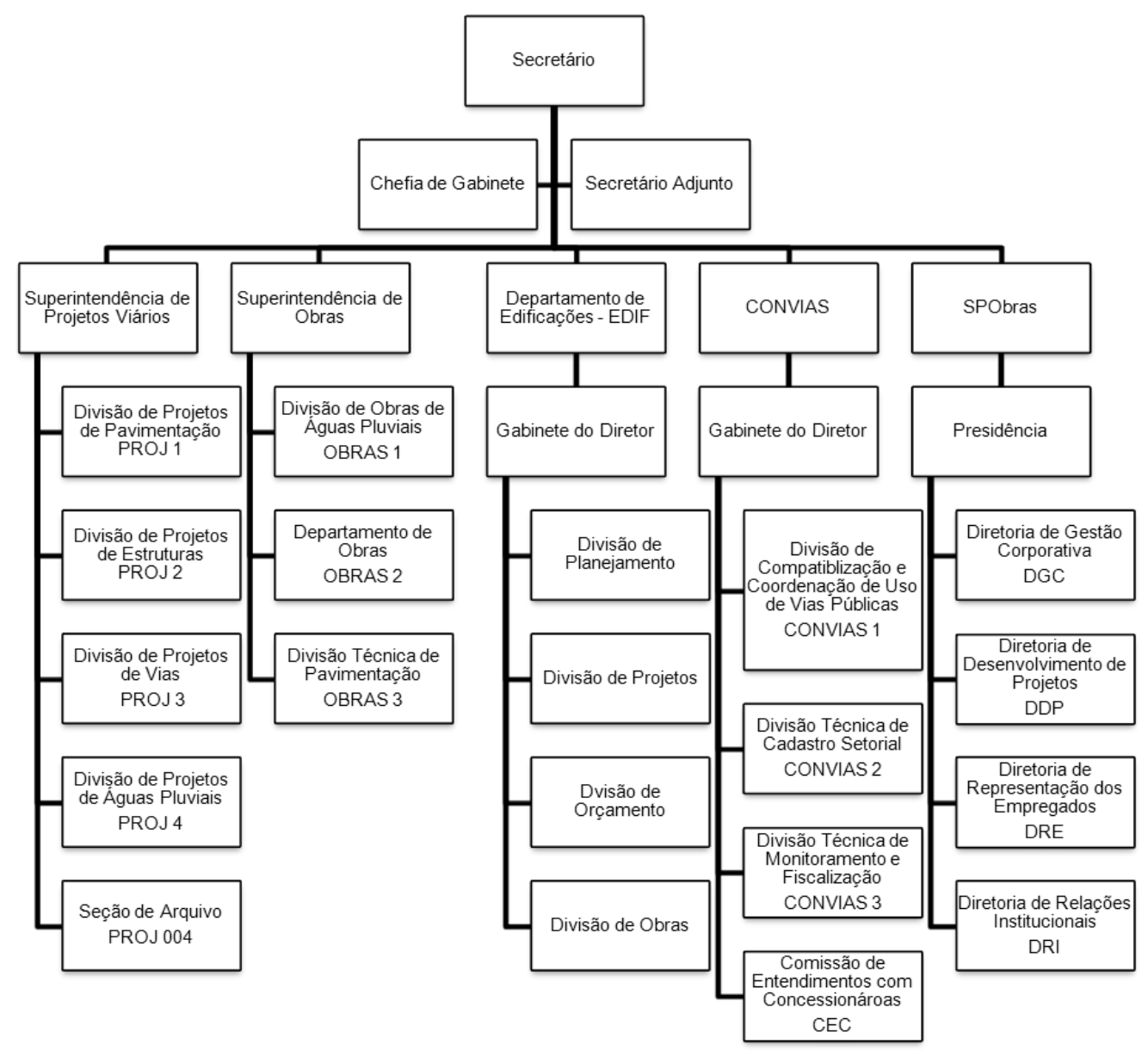


ANEXO III - Organograma do Departamento de Edificações do Município de São Paulo. 
ANEXO III - Organograma do Departamento de Edificações do Município de São Paulo

Organograma montado a partir das informações contidas no site oficial do município, link "SIURB - Secretaria de Infraestrutura Urbana e Obras do Município de São Paulo".

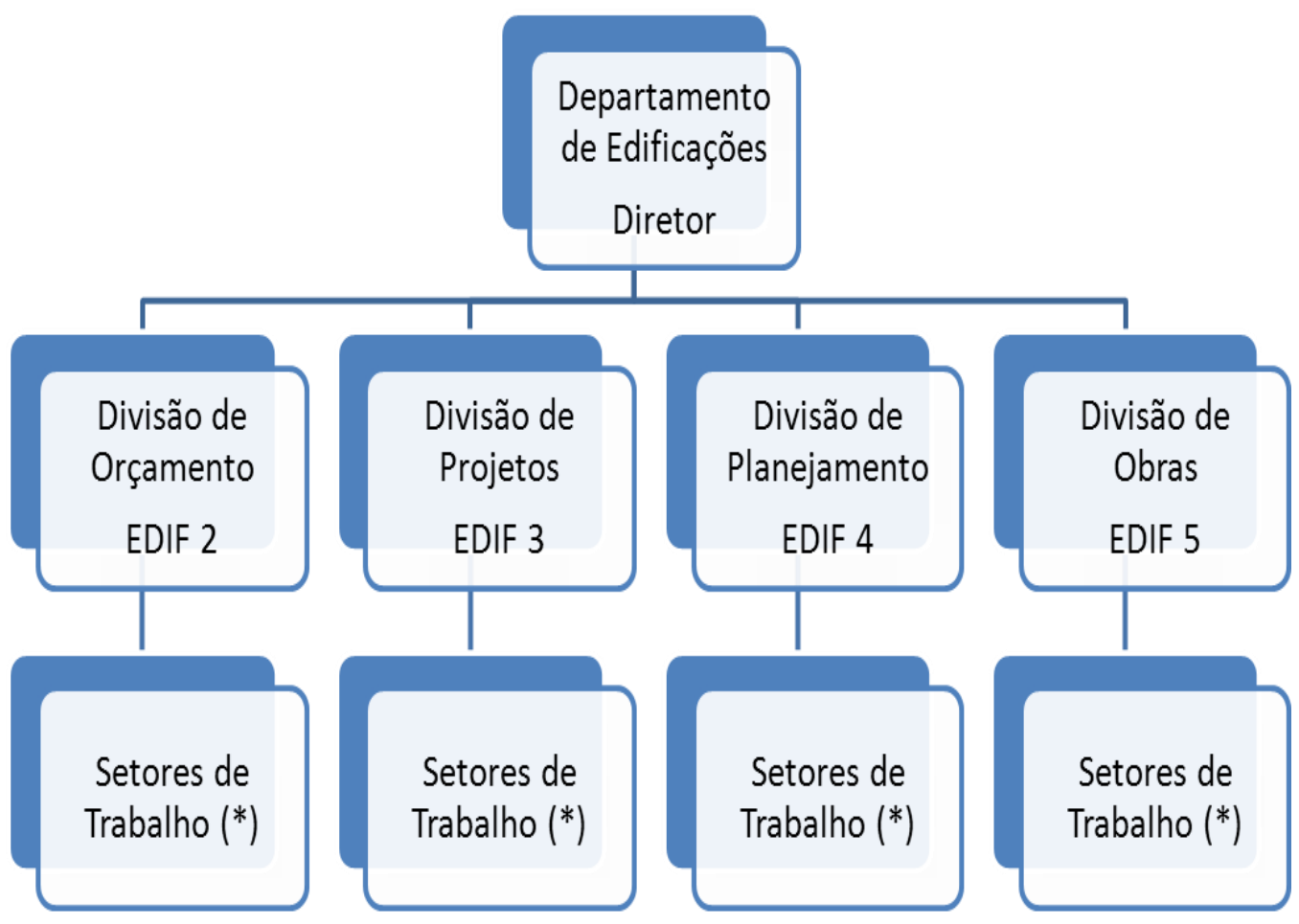

(*) Divisão informal de trabalhos de acordo com especificidades. 
ANEXO IV (Parte A) - Organograma da Companhia de Engenharia de Tráfego. 
ANEXO IV (Parte A) - Organograma da Companhia de Engenharia de Tráfego. Organograma montado a partir com informações do site oficial do município, $\underline{\text { www.cetsp.com.br }}$

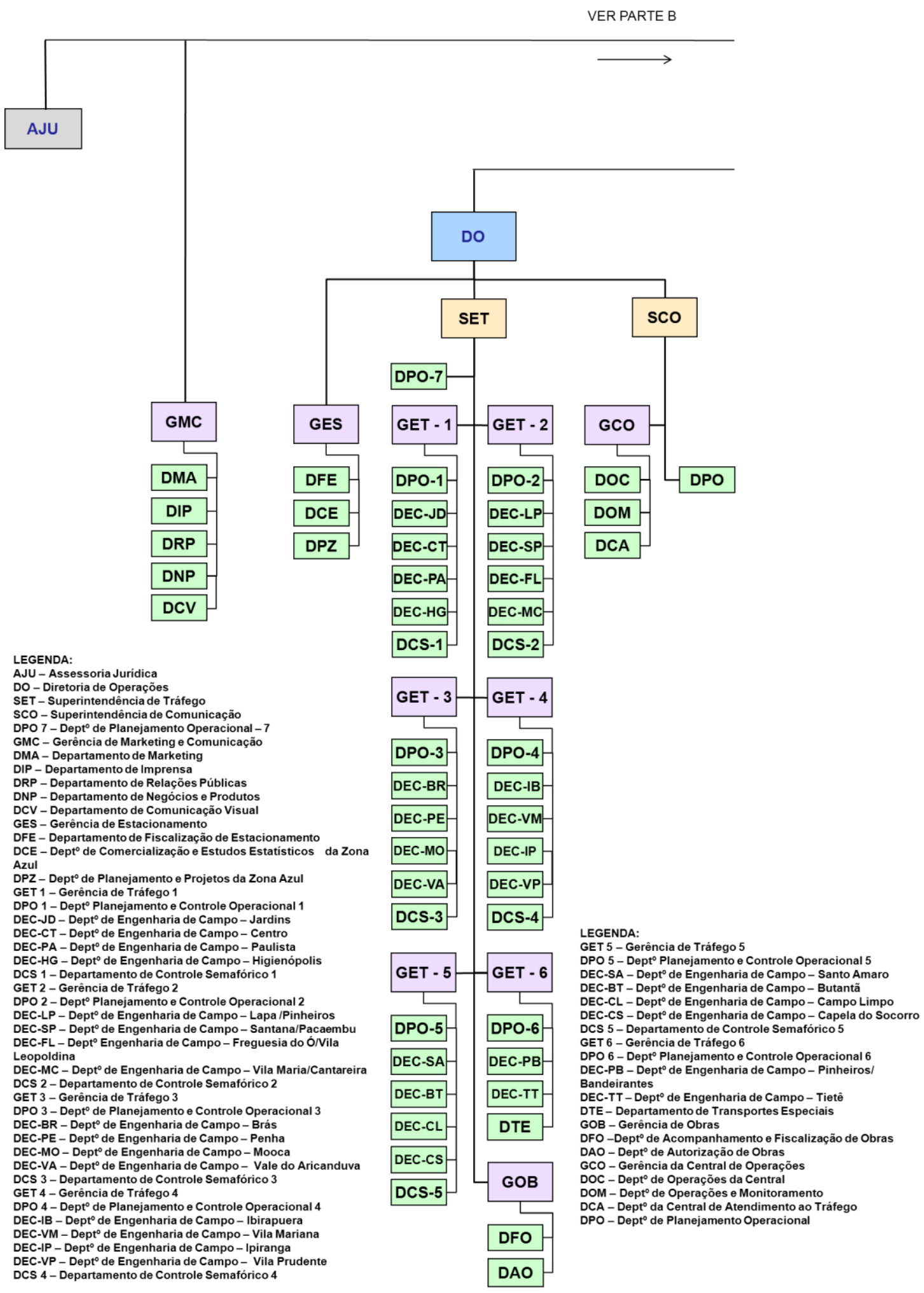


ANEXO IV (Parte B) - Organograma da Companhia de Engenharia de Tráfego. 
ANEXO IV (Parte B) - Organograma da Companhia de Engenharia de Tráfego. Organograma montado a partir com informações do site oficial do município, $\underline{\text { www.cetsp.com.br }}$

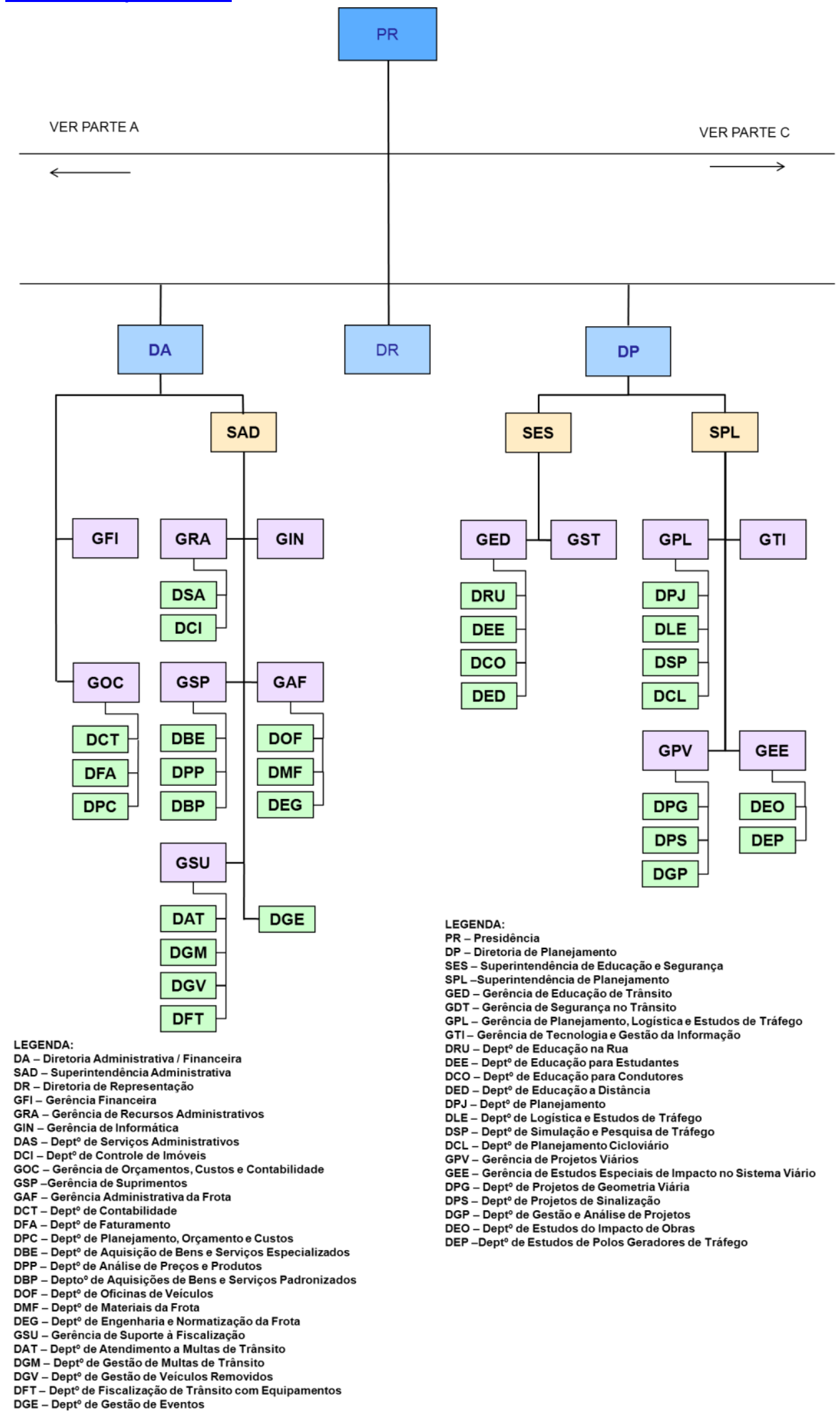


ANEXO IV (Parte C) - Organograma da Companhia de Engenharia de Tráfego. 
ANEXO IV (Parte C) - Organograma da Companhia de Engenharia de Tráfego. Organograma montado a partir com informações do site oficial do município, www.cetsp.com.br

VER PARTE B

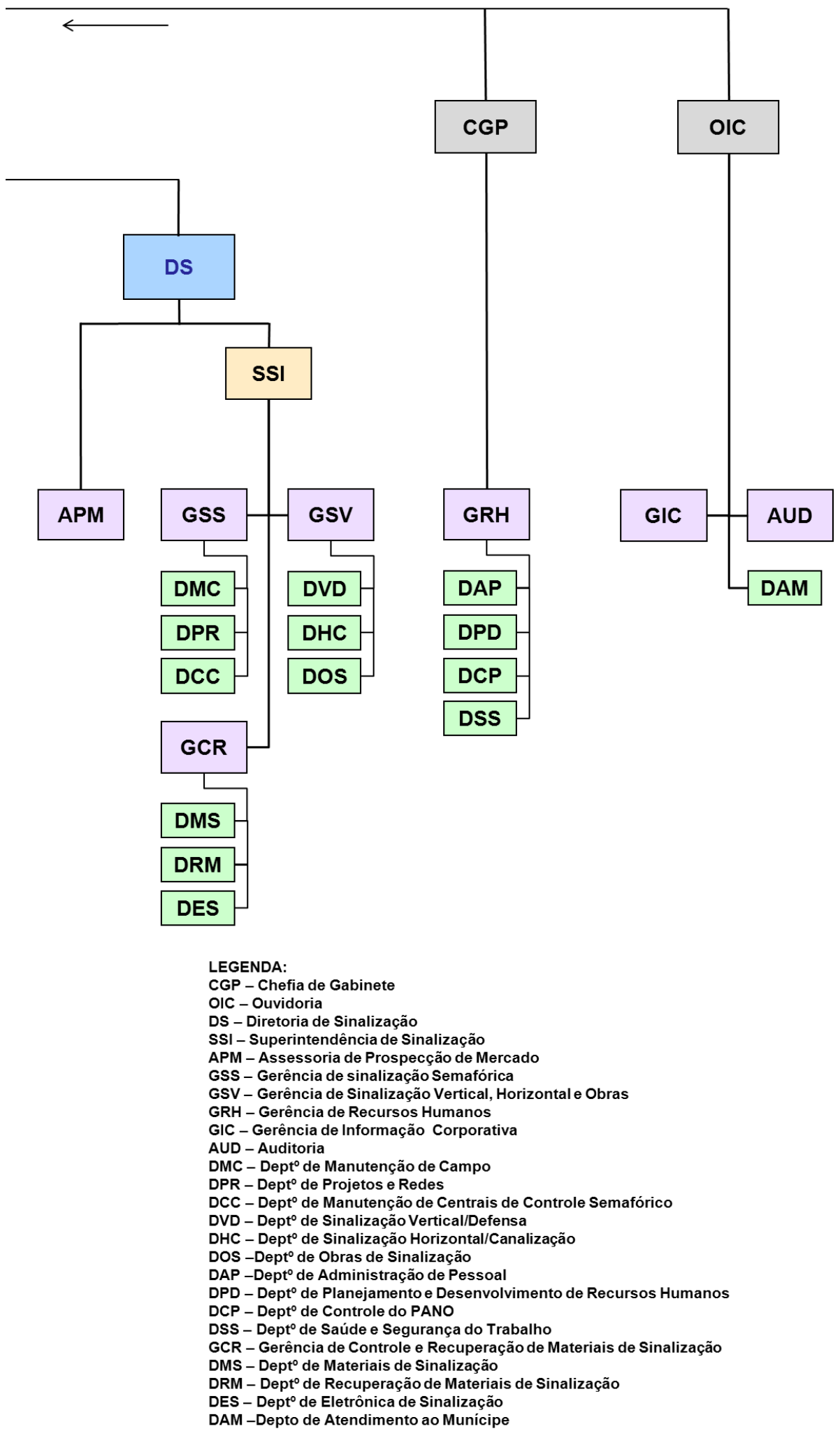


ANEXO V (PARTE A) - Fluxograma das ações necessárias para um processo de execução de obras pelo Departamento de Edificações do Município. 
ANEXO V (PARTE A) - Fluxograma das ações necessárias para um processo de execução de obras pelo Departamento de Edificações do Município.

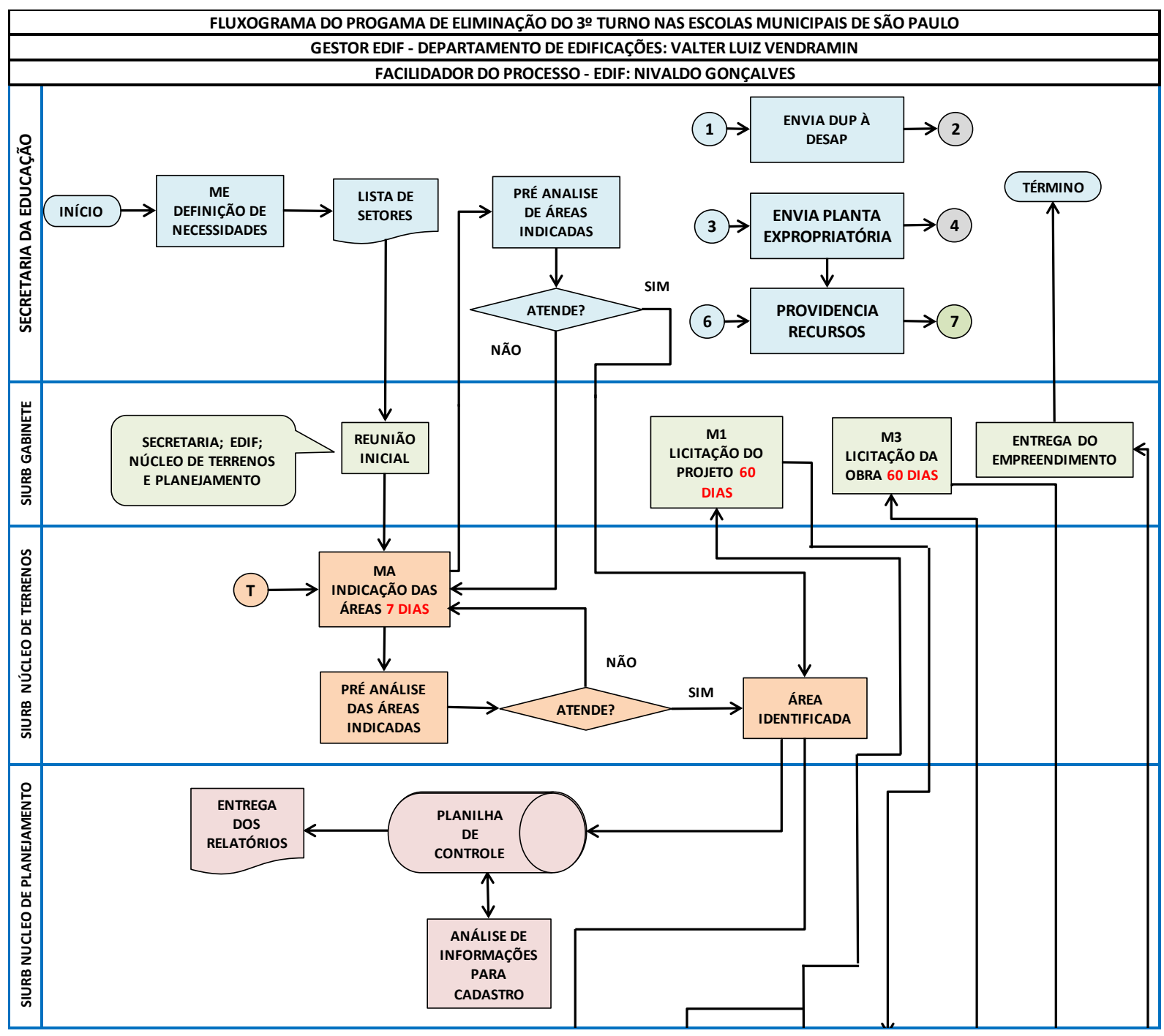


ANEXO V (PARTE B) - Fluxograma das ações necessárias para um processo de execução de obras pelo Departamento de Edificações do Município. 
ANEXO V (PARTE B) - Fluxograma das ações necessárias para um processo de execução de obras pelo Departamento de Edificações do Município.

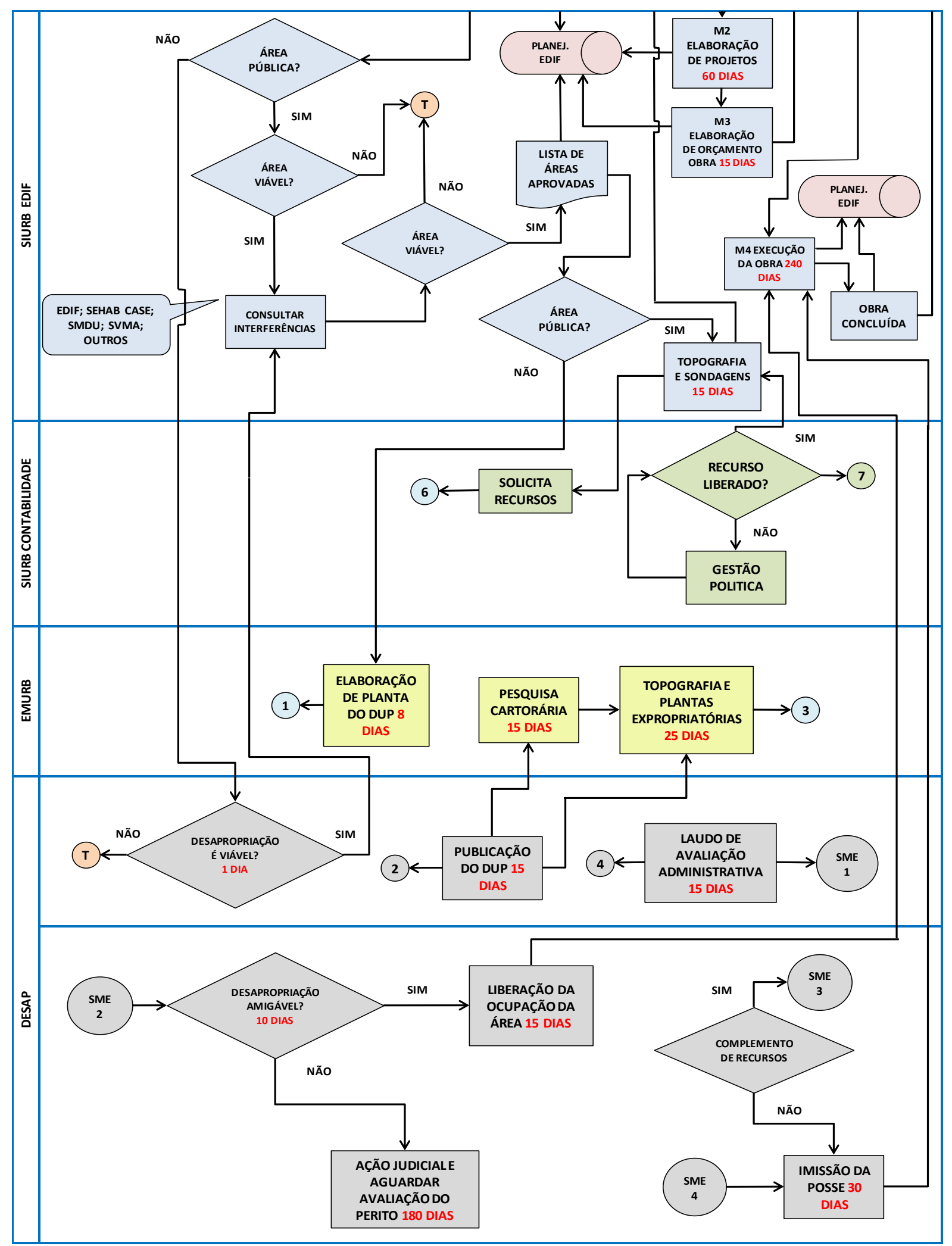


ANEXO VI - Esquema gráfico da Rede de Petri para as ações necessárias para um processo de execução de obras pelo Departamento de Edificações do Município. 
ANEXO VI - Esquema gráfico da Rede de Petri para as ações necessárias para um processo de execução de obras pelo Departamento de Edificações do Município.

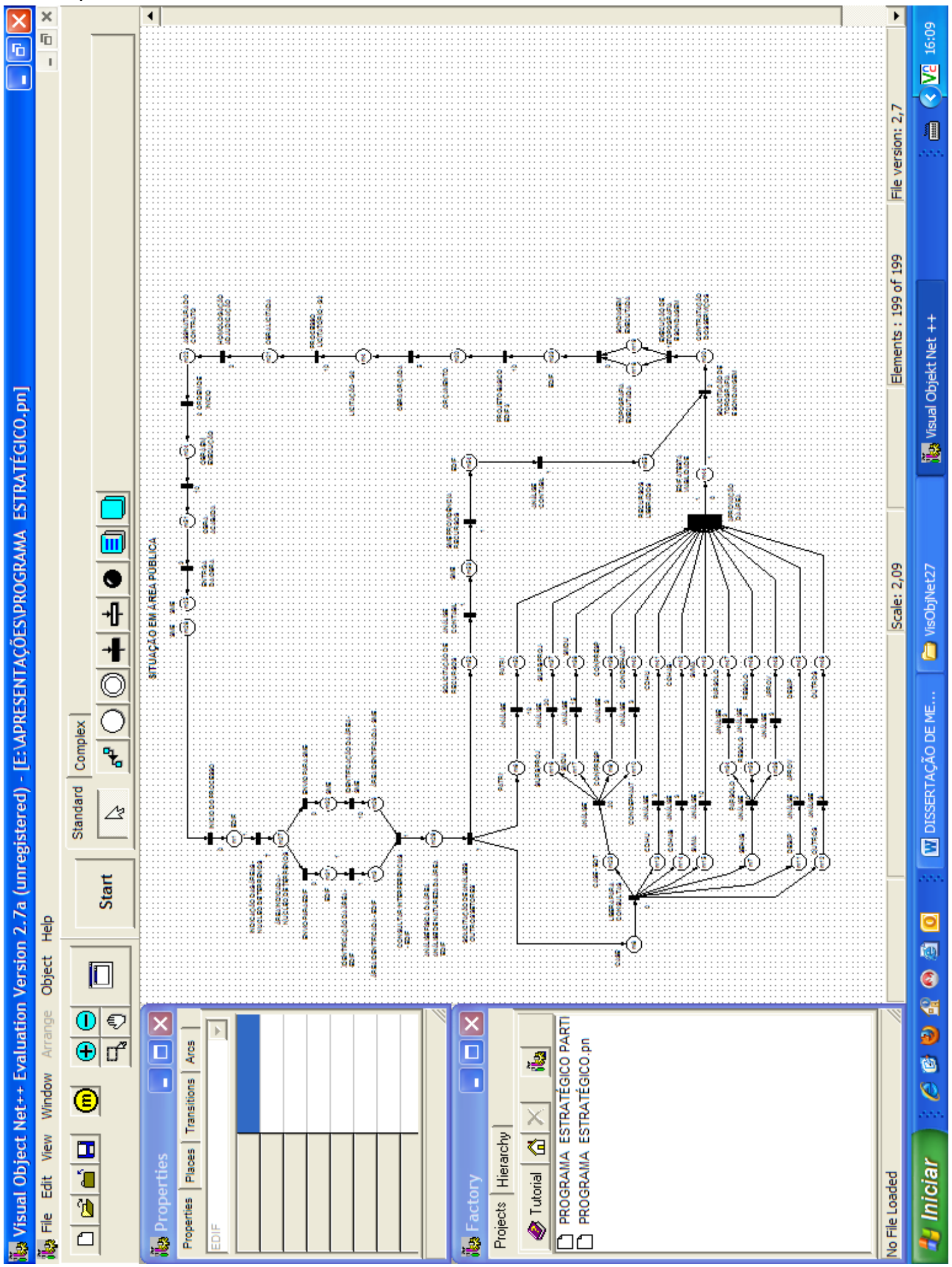


Anexo VII (Parte A) - Gravuras ilustrativas de todos os passos préconcebidos de uma visita para diagnósticos. 
Anexo VII (Parte A) - Gravuras ilustrativas de todos os passos pré-concebidos de uma visita para diagnósticos.
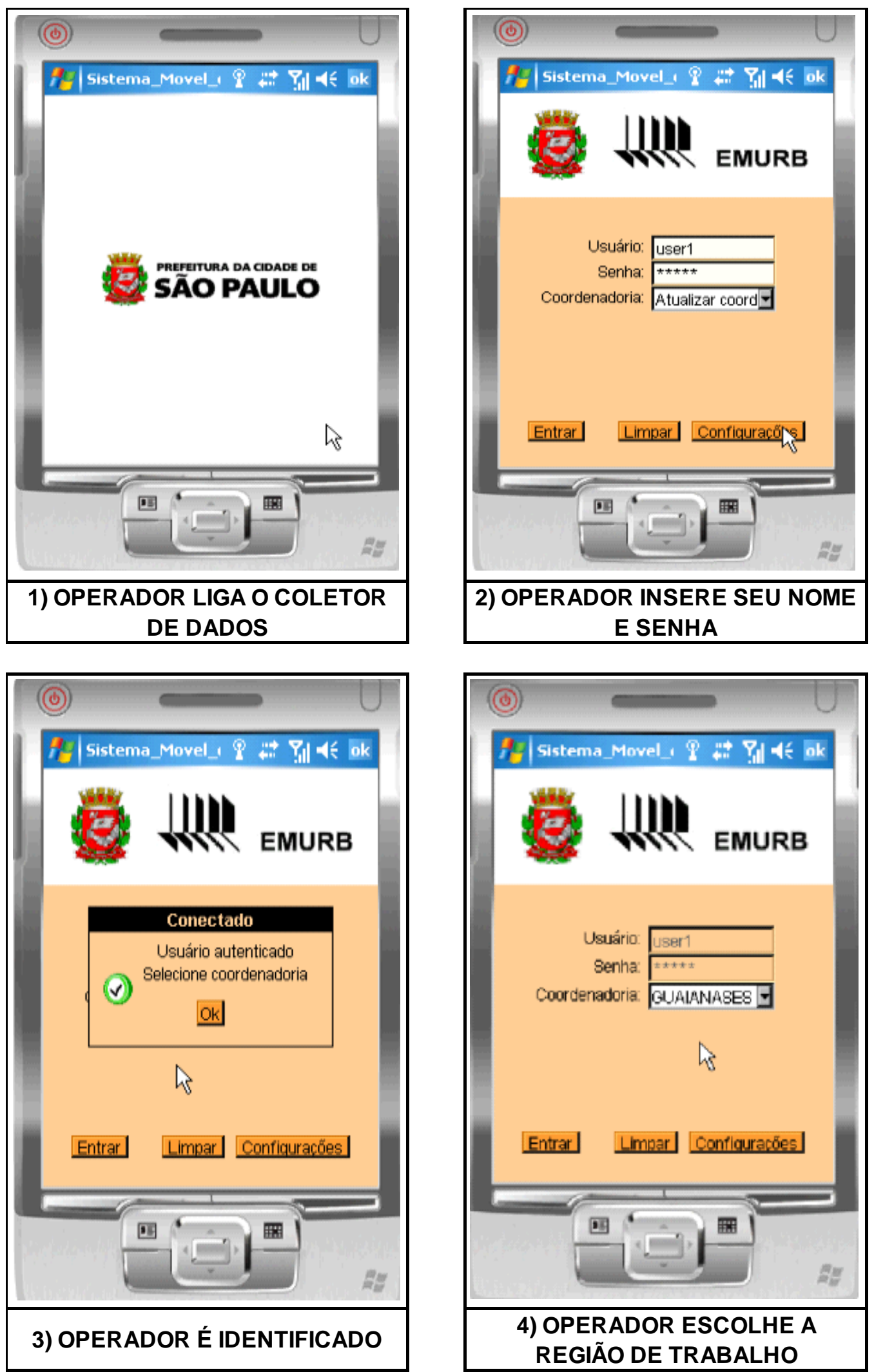
Anexo VII (Parte B) - Gravuras ilustrativas de todos os passos pré-concebidos de uma visita para diagnósticos. 
Anexo VII (Parte B) - Gravuras ilustrativas de todos os passos pré-concebidos de uma visita para diagnósticos.
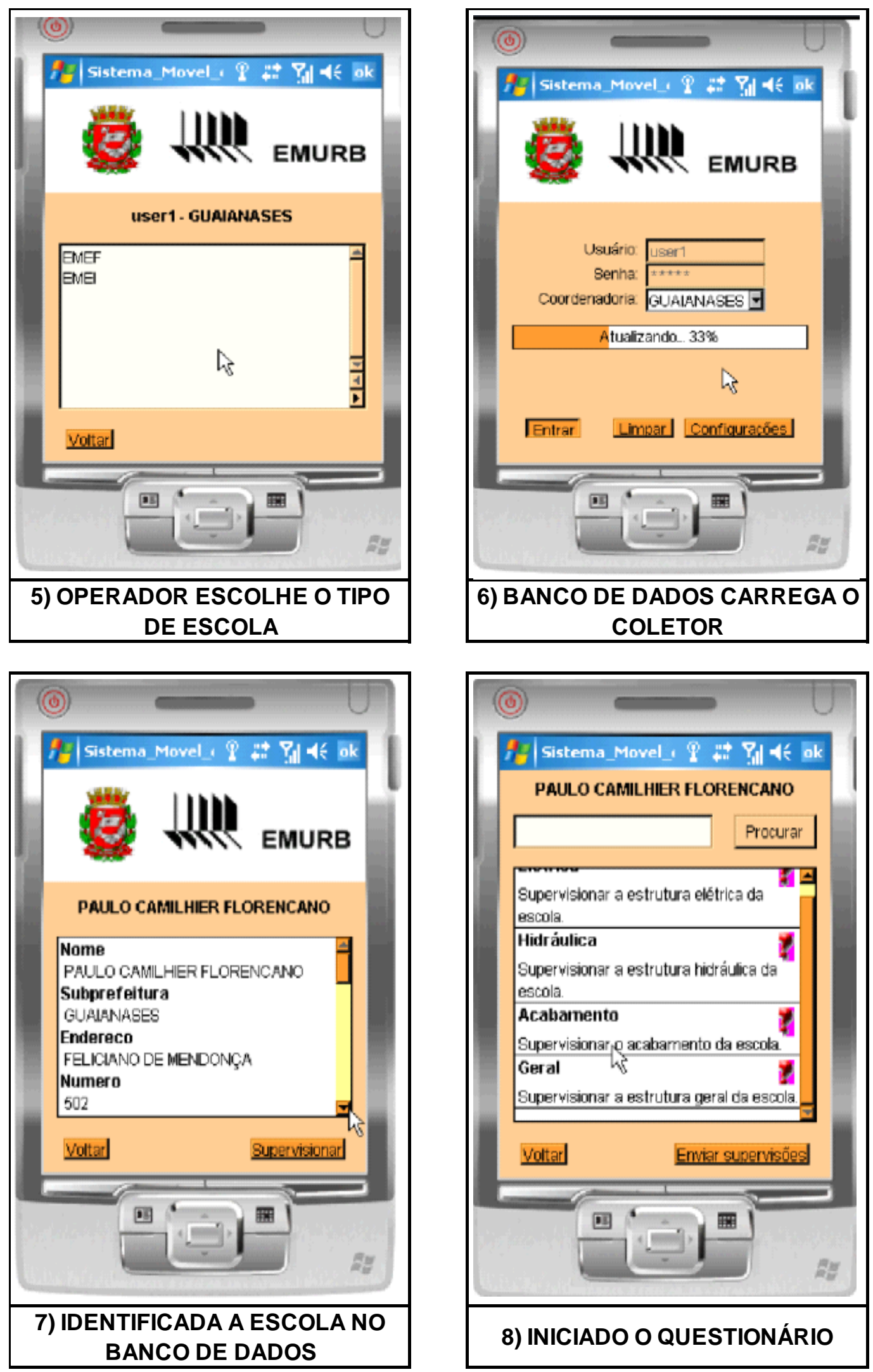
Anexo VII (Parte C) - Gravuras ilustrativas de todos os passos préconcebidos de uma visita para diagnósticos. 
Anexo VII (Parte C) - Gravuras ilustrativas de todos os passos pré-concebidos de uma visita para diagnósticos.
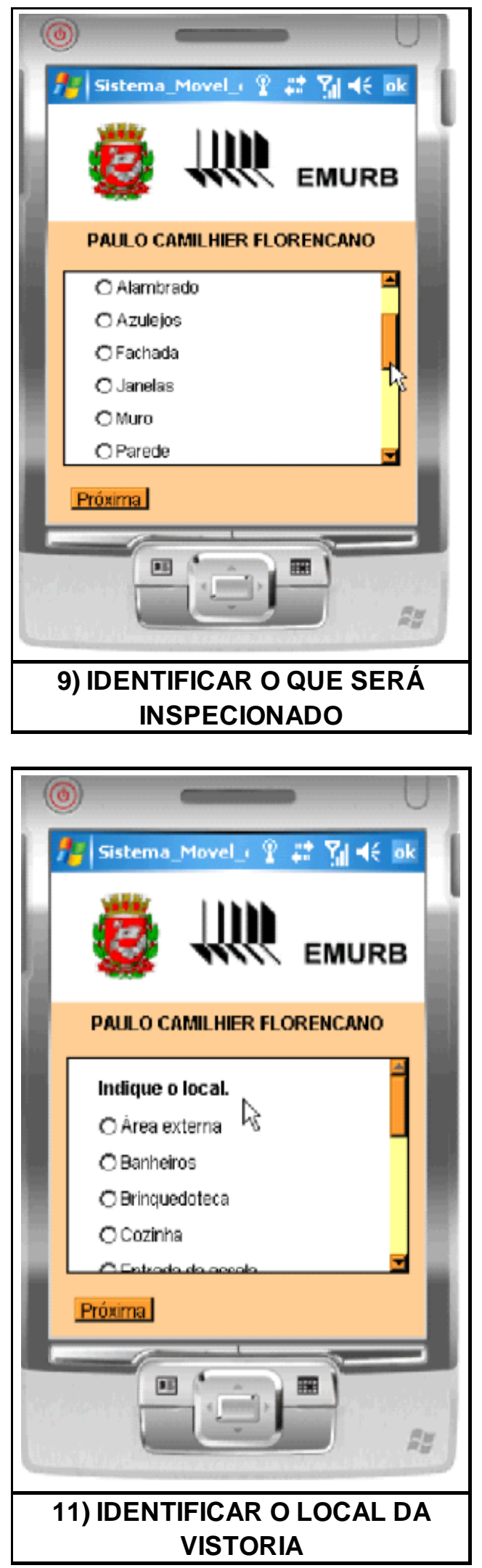
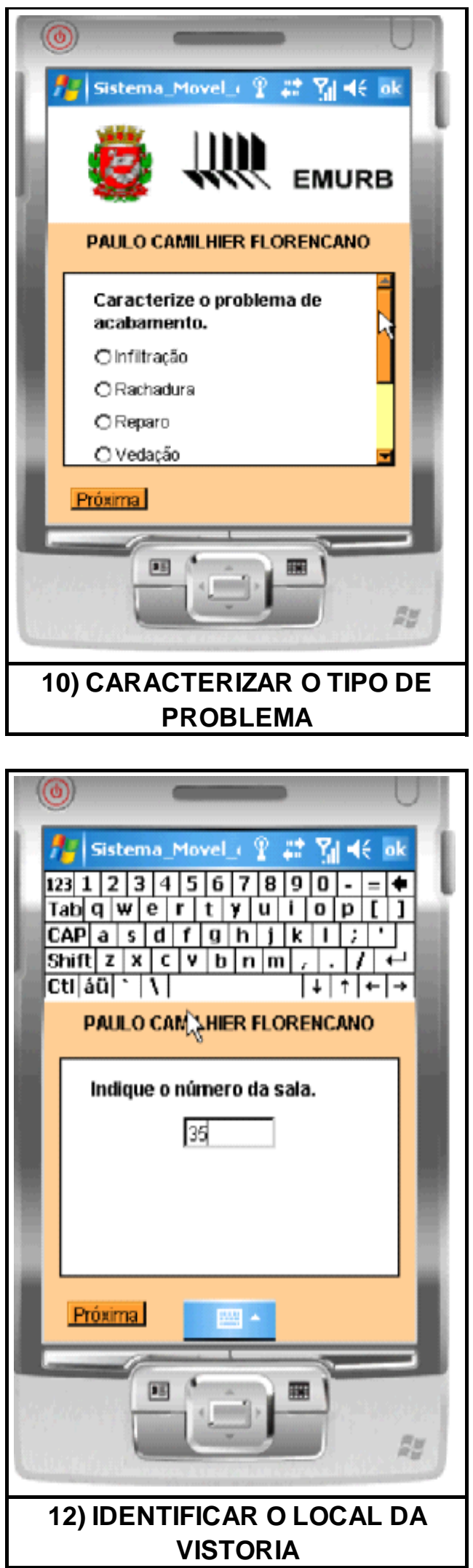
Anexo VII (Parte D) - Gravuras ilustrativas de todos os passos préconcebidos de uma visita para diagnósticos. 
Anexo VII (Parte D) - Gravuras ilustrativas de todos os passos pré-concebidos de uma visita para diagnósticos.
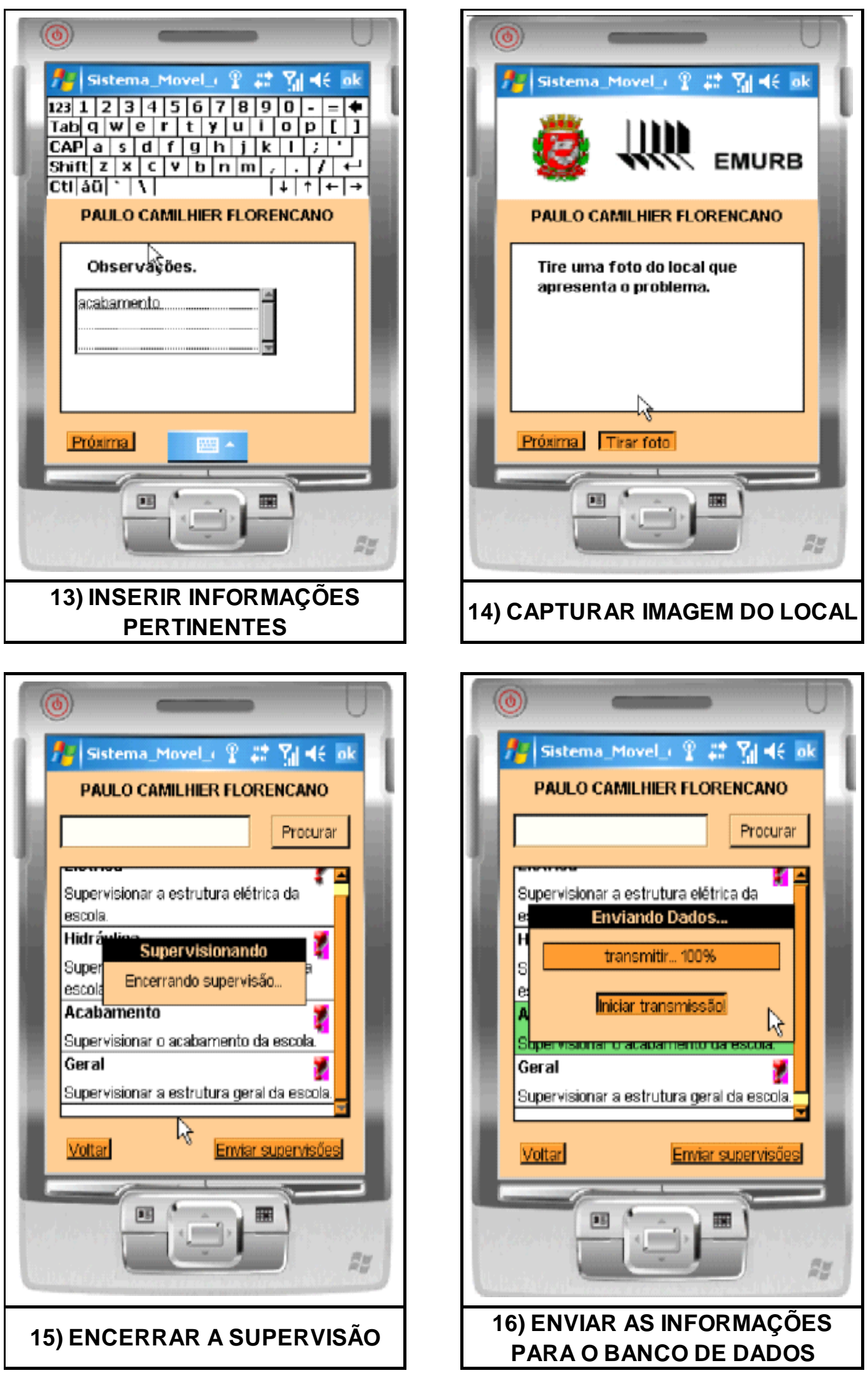